\title{
Response of Sorghum Enhanced in Monolignol Biosynthesis to Stalk Rot Pathogens
}

\author{
Deanna L. Funnell-Harris, ${ }^{1,2, \dagger}$ Scott E. Sattler, ${ }^{1,3}$ Patrick M. O’Neill, ${ }^{1,2}$ Tammy Gries, ${ }^{1,3}$ Hannah M. Tetreault, ${ }^{1,3}$ and \\ Thomas E. Clemente ${ }^{3}$ \\ ${ }^{1}$ Wheat, Sorghum and Forage Research Unit, United States Department of Agriculture-Agricultural Research Service (USDA-ARS), \\ Lincoln, NE 68583 \\ ${ }^{2}$ Department of Plant Pathology, University of Nebraska, Lincoln, NE 68583 \\ ${ }^{3}$ Department of Agronomy and Horticulture, University of Nebraska, Lincoln, NE 68583
}

\begin{abstract}
To increase phenylpropanoid constituents and energy content in the versatile $\mathrm{C}_{4}$ grass sorghum (Sorghum bicolor [L.] Moench), sorghum genes for proteins related to monolignol biosynthesis were overexpressed: SbMyb60 (transcriptional activator), SbPAL (phenylalanine ammonia lyase), SbCCoAOMT (caffeoyl coenzyme A [CoA] 3-O-methyltransferase), $\mathrm{Bmr} 2$ (4-coumarate:CoA ligase), and $\mathrm{SbC} 3 \mathrm{H}$ (coumaroyl shikimate 3-hydroxylase). Overexpression lines were evaluated for responses to stalk pathogens under greenhouse and field conditions. Greenhousegrown plants were inoculated with Fusarium thapsinum (Fusarium stalk rot) and Macrophomina phaseolina (charcoal rot), which cause yield-

two SbCCoAOMT lines. M. phaseolina-inoculated overexpression lines had lesions not significantly different from wild-type except one $S b P A L$ line (of two lines studied) with mean lesion lengths significantly larger. Field-grown $S b M y b 60$ and $S b C C o A O M T$ overexpression plants were inoculated with $F$. thapsinum. Mean lesions of $S b M y b 60$ lines were similar to wild-type, but one $S b C C o A O M T$ had larger lesions, whereas the other line was not significantly different than wild-type. Because overexpression of $S b M y b 60, B m r 2$, or $S b C 3 H$ may not render sorghum more susceptible to stalk rots, these lines may provide sources for development of sorghum with increased phenylpropanoid concentrations.
\end{abstract} reducing diseases. $F$. thapsinum-inoculated overexpression plants had mean lesion lengths not significantly different than wild-type, except for significantly smaller lesions on two of three $S b M y b 60$ and one of

Keywords: fungi, sorghum, resistance, monolignol biosynthesis, Fusarium thapsinum, Macrophomina phaseolina

The $\mathrm{C}_{4}$ grass sorghum (Sorghum bicolor [L.] Moench) is being used for feed, forage, food, and feedstock for bioenergy platforms. Grain and sweet sorghum are currently being used for grain- and juice-based ethanol production to supplement corn or sugarcane, respectively (Teixeira et al. 2017; K. Zhang et al. 2017). However, biomass from forage or energy sorghums, or bagasse from sweet sorghum, also has huge bioenergy potential (Ameen et al. 2017; Barcelos et al. 2016). Lignocellulosic ethanol can be effectively produced from sorghum biomass, particularly if processes reduce the negative impacts of lignin, which can impair enzyme access to hemicellulose, one of two cell wall polysaccharides (Scully et al. 2016).

However, lignin and the phenolic intermediates of the phenylpropanoid pathway incorporated into the cell wall have greater energy potential than the two cell wall polysaccharides, cellulose and hemicellulose (Boateng et al. 2008). Alternatives to lignocellulosic ethanol for energy production involve thermochemical conversion of biomass through pyrolysis to biocrude oil, liquid and gaseous

${ }^{\dagger}$ Corresponding author: D. L. Funnell-Harris;

Deanna.Funnell-Harris@ars.usda.gov

Funding: This work was supported by United States Department of Agriculture (USDA), Agricultural Research Service Current Research Information System project number 3042-21220-033-00D and by USDA National Institute of Food and Agriculture Competitive Grant nos. 2011-67009-30026 and 2016-67009-25420.

*The $\boldsymbol{e}$-Xtra logo stands for "electronic extra" and indicates that two supplementary figures and three supplementary tables are published online.

The author(s) declare no conflict of interest.

Accepted for publication 2 April 2019.

This article is in the public domain and not copyrightable. It may be freely reprinted with customary crediting of the source. The American Phytopathological Society, 2019. (syngas and hydrogen) (Azadi et al. 2013), or using cofiring technologies to increase efficiency and environmental quality of fossil fuel-generated electricity (Madanayake et al. 2017). It would be advantageous to increase phenylpropanoid content of biomass in order to increase its energy content for thermoconversion platforms. However, there has been increasing interest recently in developing ways to valorize lignin for a range of applications (Ragauskas et al. 2014; Wu et al. 2017; Xie et al. 2015).

The monolignol biosynthesis pathway produces three major lignin subunits ( $p$-coumaryl, coniferyl, and sinapyl) that yield, respectively, three forms of lignin: $p$-hydroxyphenyl $(\mathrm{H})$, guaiacyl $(\mathrm{G})$, and syringyl (S) (Fig. 1). Specific steps of the monolignol pathway have been characterized in sorghum (Bout and Vermerris 2003; Eudes et al. 2017; Saballos et al. 2012; Sattler et al. 2009; Scully et al. 2016, 2018; Walker et al. 2013). Three steps linked to the brown midrib phenotype are particularly well-studied. Sorghum brown midrib (bmr) mutants have reddish-brown leaf midribs instead of white or green midribs of wild-type sorghum, and this mutant phenotype has long been associated with reduced lignin content and altered lignin composition (Palmer et al. 2008; Pillonel et al. 1991; Saballos et al. 2012). Bmr6 and Bmrl2 encode a cinnamyl alcohol dehydrogenase (CAD) and a caffeic acid $O$-methyltransferase (COMT) that catalyze the last step synthesizing all three monolignols, and the penultimate step synthesizing sinapyl aldehyde, respectively (Fig. 1). $B m r 2$ encodes for 4-coumarate:coenzyme A [CoA] ligase (4CL), which catalyzes the formation of 4-coumaroyl $\mathrm{CoA}$, a substrate in the synthesis of both flavonoids and monolignols (Saballos et al. 2012). Recently, sorghum overexpressing the transcription factor, SbMyb60, or the monolignol biosynthesis pathway enzyme, caffeoyl

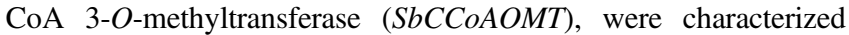
(Scully et al. 2016, 2018; Tetreault et al. 2018) (Fig. 1). The SbMyb60 transcription factor activates many of the genes encoding enzymes in the monolignol biosynthesis pathway (Scully et al. 2016, 2018). Overexpression of $S b M y b 60$ also significantly increased lignin content and altered cell wall composition, and it activated genes involved in biosynthesis of aromatic amino acids and S-adenosyl methionine 
(SAM), which are substrates and a cofactor, respectively, necessary for monolignol biosynthesis. In addition, $S b M y b 60$ overexpression affected expression of genes involved in nitrogen assimilation and carbon metabolism, presumably to redirect carbon and nitrogen toward monolignol biosynthesis (Scully et al. 2018). The enzyme $\mathrm{SbCCoAOMT}$ is a SAM-dependent $O$-methyltransferase that catalyzes the formation of feruloyl-CoA required for synthesis of both G- and S-lignin (Tetreault et al. 2018). Interestingly, overexpression of $S b C C o A O M T$ did not affect lignin content nor alter lignin composition; however, biomass total energy availability was significantly increased owing to increased soluble and cell wall-bound ferulic and sinapic acids.

Lignin and other phenylpropanoid metabolites have long been implicated in plant defense (Naoumkina et al. 2010; Nicholson and Hammerschmidt 1992; Walter 1992) as induced or extant physical barriers within the cell walls to limit pathogen ingress (Uloth et al. 2015; Wuyts et al. 2007; Y. Zhang et al. 2017) and antimicrobial or signaling molecules directly or indirectly inhibiting pathogen progression (Chang et al. 2015; Gunnaiah and Kushalappa 2014; Naoumkina et al. 2010). However, the role of these plant constituents became more complex in sorghum when bmr6, bmr12, and bmr6 bmr12 double mutant lines, significantly reduced in lignin content (Oliver et al. 2005; Pedersen et al. 2008), were compared with near-isogenic wild-type lines for responses to sorghum fungal stalk pathogens. None of the $b m r$ lines were shown to be more susceptible to the pathogens, and in some cases the $b m r$ lines were more resistant to a given pathogen, under greenhouse or field conditions (Funnell and Pedersen 2006; Funnell-Harris et al. 2010, 2014, 2017, 2018). Analyses of cell wall-bound and soluble phenolic compounds showed that $b m r$ lines accumulated significantly more phenolic compounds derived from monolignol biosynthesis than near-isogenic wild-type lines (Palmer et al. 2008). These phenolic acids were shown to be inhibitory to sorghum fungal pathogens in vitro at biological concentrations (Funnell-Harris et al. 2014). However, soluble extracts from bmr6 stalks did not inhibit in vitro growth of the virulent stalk pathogen Fusarium thapsinum Klittich, J.F. Leslie, P.E.
Nelson \& Marasas 1997 (= Gibberella thapsina Klittich, J.F. Leslie, P.E. Nelson \& Marasas 1997), which suggested that cell wall-bound phenolics or these compounds acting as signals to trigger defenserelated pathways are also involved in the increased resistance observed in the $b m r$-pathogen interactions (Funnell-Harris et al. 2017). Therefore, overexpression of monolignol biosynthetic genes or the pathway transcriptional activator, $S b M y b 60$, could alter how sorghum plants respond to stalk pathogens leading to either increased or decreased resistance.

Sorghum stalk diseases are huge problems worldwide that cause reduced grain, biomass, and sugar yield and quality (Bandara et al. 2017b, 2018; Rajewski and Francis 1991), and the increased propensity of infected plants to lodge further reduces yield (Claflin and Giorda 2002; Mughogho and Rosenberg 1984). Fusarium stalk rot, which is caused by several Fusarium species (Bandara et al. 2017c; Claflin and Giorda 2002; Funnell-Harris et al. 2017; Kelly et al. 2017; Mughogho and Rosenberg 1984) and degrades the stalk pith, likely negatively affects translocation of water and nutrients (Claflin and Giorda 2002; Reed et al. 1983). Charcoal rot, which is caused by Macrophomina phaseolina (Tassi) Goid. 1947, also triggers deterioration of the stalk, and the remaining vascular bundles become covered in dark mycelia with small black sclerotia as it progresses, which gives the disease its name (Kumari et al. 2015; Mughogho and Rosenberg 1984; Rao et al. 1980). Because of the numerous pathogens causing sorghum stalk rots and their multiple hosts, classical gene-for-gene resistance is not possible (Bandara et al. 2016; Rao et al. 1980; Tesso et al. 2010). Development of sorghum with antimicrobial cell wall components or enhanced defense signaling may be an alternative breeding approach.

For the current study, the genes encoding phenylalanine ammonia lyase, 4CL, and coumaroyl shikimate 3-hydroxylase ( $\mathrm{SbPAL}, \mathrm{Bmr}$, and $\mathrm{SbC} 3 \mathrm{H}$, respectively; Fig. 1) in sorghum were overexpressed in the sorghum line RTx430. Phenylalanine ammonia lyase (PAL) (EC 4.3.1.24) catalyzes the reversible first step of the pathway, the nonoxidative deamination of phenylalanine, to produce trans-cinnamic acid (Fig. 1), which is also used for production of flavonoids and

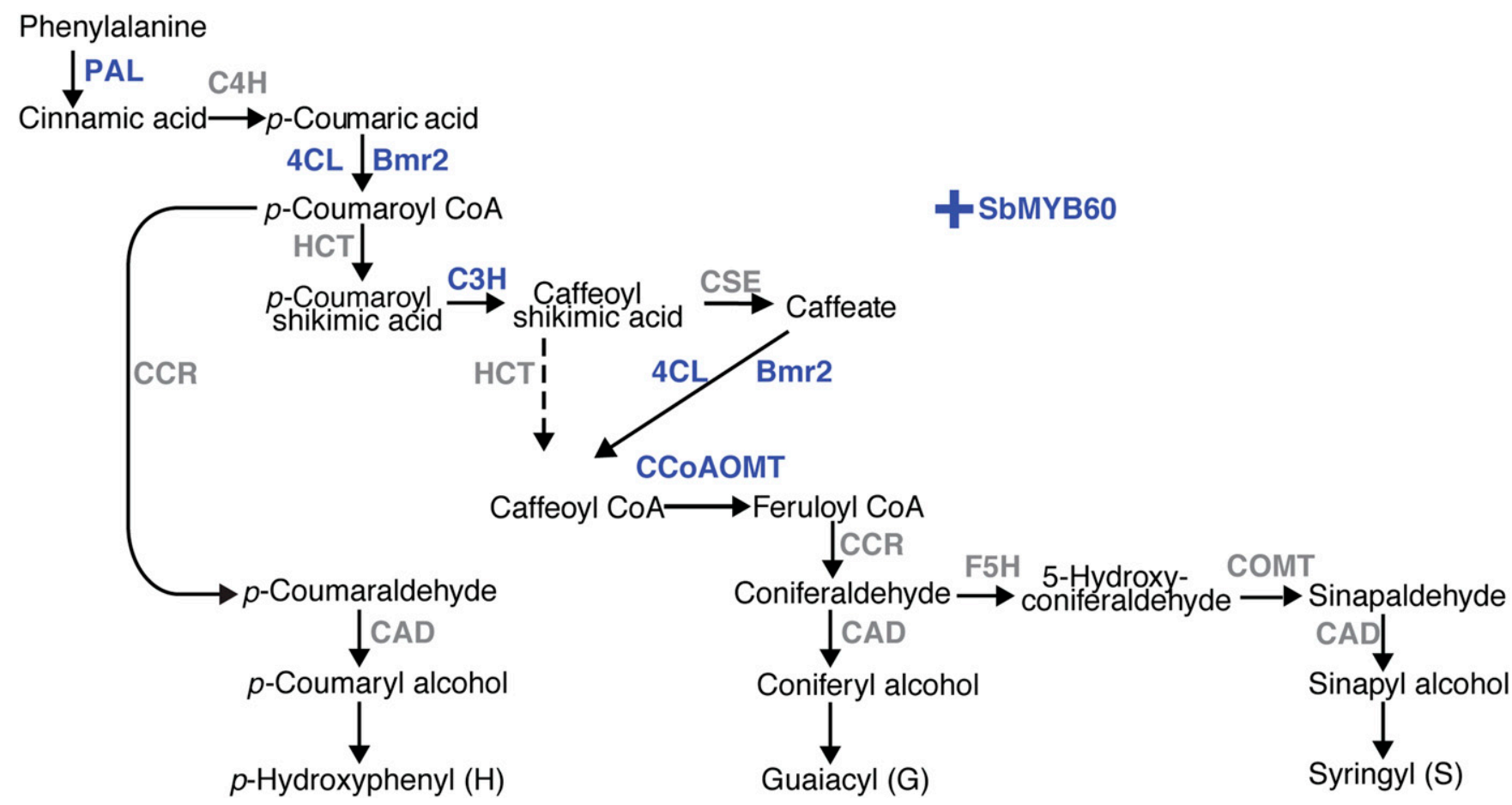

Fig. 1. Schematic of the monolignol biosynthesis pathway, the subunits that are incorporated into the lignin polymer. In sorghum, the transcription factor SbMyb60 controls expression of genes for the enzymes in the pathway. Sorghum (RTx430) was transformed with overexpressed SbMyb60, and SbPAL, SbCCOAOMT, Bmr2, and SbC3H, which encode for phenylalanine ammonia lyase (PAL), caffeoyl coenzyme A (CoA) 3-0-methyltransferase, 4-coumarate:CoA ligase (4CL), and p-coumarate 3-hydrolylase $(\mathrm{C} 3 \mathrm{H})$, respectively (highlighted in purple). $\mathrm{C} 4 \mathrm{H}=$ cinnamate 4-hydroxylase; $\mathrm{CSE}=$ caffeoyl shikimate esterase; $\mathrm{HCT}=$ hydroxycinnamoyl-CoA shikimate transferase; $\mathrm{CCR}=$ cinnamoyl-CoA reductase; $\mathrm{F} 5 \mathrm{H}$ = ferulate 5-hydroxylase; $\mathrm{COMT}$ = caffeic acid O-methyltransferase; and CAD = cinnamyl alcohol dehydrogenase. 
other phenylpropanoids (Cui et al. 2014). The coumaroyl shikimate 3-hydroxylase enzyme (C3H) (EC 2.1.1.104) is one of three membrane-bound cytochrome $\mathrm{P} 450$ monolignol enzymes and central for the formation of G- and S-lignin (Fornalé et al. 2015; Reddy et al. 2005). PAL, 4CL, and $\mathrm{C} 3 \mathrm{H}$ have been implicated in defense responses to pathogens (Bhuiyan et al. 2009; Franke et al. 2002; Moerschbacher et al. 1986; Reinold and Hahlbrock 1996; Steiner et al. 2009).

Transgenic lines overexpressing $S b P A L, B m r 2, S b C 3 H, S b M y b 60$, or $S b C C O A O M T$, along with the wild-type line, RTx430, were assessed for responses to the stalk rot pathogens $F$. thapsinum and $M$. phaseolina under greenhouse conditions. Additionally, the $S b M y b 60$ and $S b C C O A O M T$ overexpression lines were assessed for response to $F$. thapsinum under field conditions. These assays were conducted to test the hypothesis that transgenic sorghum lines overexpressing genes in the monolignol biosynthesis pathway will have increased resistance to sorghum stalk pathogens.

\section{Materials and Methods}

Fungi. The $F$. thapsinum isolates H03-11S-9 and M05A_1J_3b were identified by using colony, conidia, and conidiophore morphology (Funnell-Harris et al. 2013) and comparing the sequence of the $5^{\prime}$ region of the translation elongation factor 1- $\alpha$ gene to the FusariumID database (http://www.fusariumdb.org/index.php) (Geiser et al. 2004) for previous studies (Funnell-Harris et al. 2010, 2018). Isolate H03-11S-9, from a field in Lincoln, NE, was used to perform greenhouse inoculations at University of Nebraska, Lincoln, whereas isolate M05A_1J_3b was used for field inoculations at Mead, NE, the same location from which it was obtained. In a previous greenhouse assessment, the two isolates had similar virulence levels (FunnellHarris et al. 2018). The M. phaseolina isolate (MP01-001), a kind gift from G. Odvody (Texas A \& M AgriLife Research and Extension Center, Corpus Christi, TX), was hyphal-tip purified before use. Medium for maintenance of working stocks was one-half strength potato dextrose agar (PDA) prepared using potato dextrose broth (Becton Dickinson and Co., Sparks, MD) and amended with $100 \mu \mathrm{M} /$ liter of ampicillin (Sigma-Aldrich, St. Louis, MO). To prepare inoculum, agar discs (5 $\mathrm{mm}$ in diameter) from the growing edge of 4-day-old cultures on PDA were inoculated into sterile full-strength potato dextrose broth (PDB) (one disc per $5 \mathrm{ml}$ of broth) with sterile toothpicks, previously treated to remove toxins and other inhibitors of fungal growth (Funnell-Harris et al. 2017, 2018; Jardine and Leslie 1992). The broth-and-toothpick cultures were incubated for 2 weeks at $25^{\circ} \mathrm{C}$ before inoculations.

Overexpression constructs and transgenic plant analyses. Overexpression constructs were transformed into sorghum RTx430, a parental line commonly used in hybrid production (http://archive. gramene.org/db/diversity/diversity_view?action=view\&object= div_passport\&id=3919\&db_name=diversity_sorghum). Generation of constructs and transgenic lines with overexpression of $S b M y b 60$ (Sobic.004G2738000) and SbCCoAOMT (Sobic.010G052200.1) has been previously described (Scully et al. 2016; Tetreault et al. 2018). For $S b M y b 60$, the coding region plus one intron was used, whereas for $S b C C O A O M T$ only the coding region was used. For $S b P A L$ (Sobic.004G220300.1) (Jun et al. 2018), SbC3H (Sobic.009G181800.1), and Bmr2 (Sobic.004G062500.1) (Saballos et al. 2012), preparation of constructs and Agrobacterium tumefaciens, and transformation of sorghum, were similar to SbCCoAOMT (Tetreault et al. 2018). The coding regions of $S b P A L$ and $S b C 3 H$ were amplified from genomic DNA. The coding region of $B m r 2$ was amplified from the pET30aBmr2 vector (Saballos et al. 2012). Each coding region was cloned into a cassette between the cauliflower mosaic virus (CaMV) E35S promoter and the $35 \mathrm{~S} \mathrm{CaMV}$ terminator (Scully et al. 2016). Each cassette was incorporated into the binary vector pPZP211, which includes antibiotic resistance and selection markers streptomycin and neomycin, respectively (Hajdukiewicz et al. 1994). Primers for amplification of genes and modification for insertion into overexpression cassettes and detection in genomic DNA of transgenic plants are listed in Supplementary Table S1, along with primers used for reverse transcription quantitative PCR (RT-qPCR) (see below).
Two independent lead events each of $S b P A L$ (out of nine independent events) and Bmr2 (out of four independent events) were chosen based on visual estimates of protein abundance on Western blots (Supplementary Fig. S1), as previously described (Tetreault et al. 2018). To identify two lead events of expression of $\mathrm{SbC} 3 \mathrm{H}$ (out of eight) that encode for $p$-coumarate 3-hydroxylase, a membraneassociated cytochrome P-450, RT-qPCR was conducted to measure transcript levels of this gene, as well as for $S b P A L$ and Bmr2 (Supplementary Fig. S2). Once $\mathrm{T}_{2}$ independent lead events were identified, each was selfed (if necessary) until homozygous lines were obtained for each overexpression construct. For RT-qPCR, total RNA was extracted from ground leaf samples using TRIzol reagent (Invitrogen, Carlsbad, CA) and purified with a Direct-zol RNA MiniPrep Kit (Zymo Research, Irvine, CA). The Transcriptor First Strand cDNA Synthesis Kit (Roche Diagnostics Corporation, Indianapolis, IN) was used to produce cDNA using $500 \mathrm{ng}$ of RNA from each sample. qPCR was performed on a CFX Connect Real-Time PCR Detection System (Bio-Rad Laboratories, Hercules, CA) using transgene-specific primers to each cDNA and conditions as previously described (Scully et al. 2016). Primers specific to sorghum $\alpha$-tubulin were used as standards. Relative expression was computed using the $\Delta \Delta \mathrm{Ct}$ method with $\alpha$-tubulin for normalization. No template and no reverse transcription controls were included to verify the absence of DNA contamination. Variation was estimated using the GLM procedure and mean values compared using Tukey's Studentized Range (HSD) test (SAS 2013). Within individual gene and wild-type comparisons were considered significantly different at $P<0.05$.

For each lead event, available energy $(\mathrm{Cal} / \mathrm{g})$ was determined for stalk tissues from 5- to 6-week-old greenhouse-grown plants using bomb calorimetry as previously described (Scully et al. 2016). Acid detergent lignin $(\mathrm{g} / \mathrm{kg})$ was determined for $S b P A L$ and $S b C 3 H$ lead events as previously described (Vogel et al. 1999). Results are shown in Supplementary Table S2.

Greenhouse stalk inoculations of lines overexpressing genes in monolignol biosynthesis. Lines used in greenhouse assessments of responses to stalk pathogens $F$. thapsinum and $M$. phaseolina included lead events for each overexpression construct. Plants overexpressing SbCCoAOMT were event numbers ZG 234-1-28b and ZG 234-3-9a (Tetreault et al. 2018) and will be referred to as SbCCoAOMT_28b and SbCCoAOMT_9a, respectively; overexpressing SbMyb60 were events ZG 129-4-10a, ZG 129-4-15a, and ZG 124-1-2a (Scully et al. 2016) and will be referred to as SbMyb_10a, SbMyb_15a, and SbMyb_2a, respectively; overexpressing $S b P A L$ were events ZG 162-1-4a and ZG 136-2-3b and will be referred to as SbPAL_3b and SbPAL_4a, respectively; overexpressing Bmr2 were events ZG 300-1-2a and ZG 300-1-6a and will be referred to as Bmr2_2a and Bmr2_6a, respectively; and plants overexpressing $S b C 3 H$ were events $\mathrm{ZG}$ 177-2-1a and ZG 170-3-1a and will be referred to as $\mathrm{SbC} 3 \mathrm{H} \_2 \mathrm{~b}$ and $\mathrm{SbC} 3 \mathrm{H} \_3 \mathrm{a}$, respectively. Included in all assays was the wild-type line, RTx430. The Myb_ 10a line is maintained as heterozygous for the transgene owing to profound delays in flowering when in the homozygous state (Scully et al. 2016); all other lines are homozygous for the transgene.

Greenhouse inoculations were conducted at the University of Nebraska Plant Growth Facilities, throughout the years of 2016 to 2018. Each set of lead events were compared for responses to $F$. thapsinum, M. phaseolina, and a broth (PDB) control with the wild-type line RTx430. Greenhouse-produced seeds were sown into 25.4-cm-diameter pots containing pasteurized soil mix (one part sand, one part coarse vermiculite, one part top soil, and two parts shredded peat moss). Seedlings of SbMyb_10a were screened using PCR to detect the presence of the transgene. All lines were culled to one plant per pot. During head emergence (when the spikelet emerges from the collar of the flag leaf) heads of all lines, including nontransgenic wild-type, were covered with pollination bags to prevent pollen release. Because of secondary effects of overexpression on some of the lines, development, especially timing of flowering, was significantly affected. In particular, SbMyb60_10a flowered nearly 20 days later than the wild-type (Scully et al. 2016). Therefore, 
SbMyb60_10a was planted in advance of the other lines so that lines were inoculated at the same time. Staggered planting of the lines is described in Supplementary Table S3, along with days after planting (DAP) for inoculations; time of year greatly affected the number of DAP to boot stage. Within 3 weeks of boot stage (when leaves are fully expanded and the head is near complete development but still enclosed in the flag-leaf sheath) at the base of each stalk, the middle of the second internode above the soil was inoculated with one of the two fungi or the PDB control, essentially as previously described (Funnell-Harris et al. 2014). A surface-disinfested awl was used to make a small hole, into which a fungus-infested toothpick, or a control toothpick, was inserted. At 32 days after inoculation (DAI) the stalk was split longitudinally, and the length of the resulting redto-purple discoloration resulting from wounding and pathogen ingress (defined as the lesion) was measured. This methodology has been commonly used in several other studies, including with plants of varying heights (Bandara et al. 2017a; Funnell-Harris et al. 2014; Tesso et al. 2005). In addition to measurements of lesion lengths, plant heights after flowering and stalk diameters at site of inoculation (middle of second internode) were determined. A total of six plantings were performed.

Data analysis. The experimental design was randomized complete block (RCB). There were three (SbMyb60 lines) or two (all other constructs) lead events and one wild-type line and three treatments in each of eight replicated blocks, with two ( $S b P A L$ lines) or three (all other lines) repetitions of each experiment. Individual plants or pots were considered the experimental unit. Replications within each experiment were blocked by location in the greenhouse. Analyses for mean lesion lengths, plant heights, and stalk diameters were performed. Replication within a repetition was treated as a random effect. Repetition, line, and inoculum were considered fixed effects. The data were analyzed using the PROC MIXED procedure of SAS/STAT software (SAS 2013). Datasets were analyzed for Levene's homogeneity of variance, and appropriate adjustments were incorporated using the REPEATED/GROUP option. Least squares means (LSM) and standard errors (SE) are reported. Differences of LSM were considered significant at $P \leq 0.05$. Pearson correlations were generated for the response variables lesion length, height, and stalk diameter using the PROC CORR procedure in SAS/STAT software.

Table 1. Plant height and basal stalk diameter at maturity of greenhousegrown wild-type and transgenic sorghum plants overexpressing monolignol pathway-associated genes

\begin{tabular}{|c|c|c|}
\hline Transgenic line ${ }^{\mathrm{z}} \mathrm{RT} \mathbf{4} 40$ & Plant height (cm) & Stalk diameter $(\mathrm{mm})$ \\
\hline SbPAL_3b & $106.2 \pm 2.4 \mathrm{~b}$ & $15.3 \pm 0.3 \mathrm{a}$ \\
\hline SbPAL_4a & $110.3 \pm 1.5 b$ & $14.8 \pm 0.3 \mathrm{a}$ \\
\hline Wild-type & $138.8 \pm 4.7 \mathrm{a}$ & $15.2 \pm 0.3 \mathrm{a}$ \\
\hline SbMyb_2a & $107.6 \pm 1.9 \mathrm{~b}$ & $15.2 \pm 0.2 \mathrm{a}$ \\
\hline SbMyb_10a & $83.9 \pm 1.9 \mathrm{c}$ & $13.9 \pm 0.3 b$ \\
\hline SbMyb_15a & $79.3 \pm 1.9 \mathrm{c}$ & $12.3 \pm 0.2 \mathrm{c}$ \\
\hline Wild-type & $126.0 \pm 2.0 \mathrm{a}$ & $14.2 \pm 0.2 b$ \\
\hline SbCCoAOMT_9a & $113.8 \pm 1.9 \mathrm{~b}$ & $15.3 \pm 0.2 \mathrm{a}$ \\
\hline SbCCoAOMT_28b & $105.8 \pm 2.0 \mathrm{c}$ & $14.2 \pm 0.2 b$ \\
\hline Wild-type & $126.0 \pm 2.0 \mathrm{a}$ & $14.2 \pm 0.2 \mathrm{~b}$ \\
\hline Bmr2_2a & $98.0 \pm 1.8 \mathrm{~b}$ & $11.9 \pm 0.2 \mathrm{a}$ \\
\hline Bmr2_6a & $82.9 \pm 2.2 \mathrm{c}$ & $8.8 \pm 0.2 \mathrm{~b}$ \\
\hline Wild-type & $102.4 \pm 1.5 \mathrm{a}$ & $11.9 \pm 0.2 \mathrm{a}$ \\
\hline SbC3H_2b & $80.9 \pm 0.9 \mathrm{c}$ & $12.0 \pm 0.2 \mathrm{a}$ \\
\hline SbC3H_3a & $89.6 \pm 1.2 \mathrm{~b}$ & $10.4 \pm 0.2 b$ \\
\hline Wild-type & $97.6 \pm 1.1 \mathrm{a}$ & $11.6 \pm 0.2 \mathrm{a}$ \\
\hline
\end{tabular}

${ }^{\mathrm{z}}$ The overexpressed monolignol pathway-associated genes were $S b M y b 60$ that encodes for the transcription factor that upregulates genes for enzymes in the monolignol biosynthesis pathway; $S b P A L$ for phenylalanine ammonia lyase; SbCCoAOMT for caffeoyl coenzyme A (CoA) 3-O-methyltransferase; $B m r 2$ for 4-coumarate: $\mathrm{CoA}$ ligase; and $\mathrm{SbC} 3 \mathrm{H}$ for coumaroyl shikimate 3hydroxylase. Letters indicate comparisons between transgenic lines carrying the same construct and the wild-type (below); values with different letters are significantly different at $P \leq 0.05$.
Field response of lines overexpressing $S b M y b 60$ and SbCCoAOMT to F. thapsinum. The SbMyb60 and SbCCoAOMT overexpression lead events and the wild-type line were planted at University of Nebraska Plant Biotechnology Field Facility, at Mead, NE, during the growing seasons of 2017 and 2018; for each year there was a repetition of the entire experiment. Seeds (160) of each transgenic line and the wild-type were mechanically planted in 6.1$m$ rows in three RCBs within a 0.05-ha plot; each of the three RCBs is considered a replication within each year. Two-and-one-half months before the 2017 planting, debris from alfalfa planted 3 years before was plowed under. The field was disked and cultivated, 2 and 1 days, respectively, before planting on June 1 . Atrazine $(1.1 \mathrm{~kg} / \mathrm{ha}$; 2-chloro- $n$-ethyl- $N^{\prime}$-[1-methyl-ethyl]-1,3,5-triazine-2,4-diamine) was applied at planting for weed control. Overhead irrigation was applied on June $7(1.3 \mathrm{~cm}), 9(3.2 \mathrm{~cm})$, and $10(0.6 \mathrm{~cm})$ and on July 10 $(2.5 \mathrm{~cm}), 11(1.9 \mathrm{~cm})$, and $20(3.1 \mathrm{~cm})$. Rainfall totals for June, July, August, and September were 9.0, 8.0, 10.8, and $8.6 \mathrm{~cm}$, respectively. For the 2018 planting (June 6), the previous crops had been corn (2017) and alfalfa (2016). The field was cultivated 2 days before planting. Atrazine was applied at planting, and then, 1 month after planting, the plots were fertilized with urea $(90.8 \mathrm{~kg} / \mathrm{ha})$. Irrigation was applied June $7(1.3 \mathrm{~cm})$, June $14(2.5 \mathrm{~cm})$, and August 17 $(2.5 \mathrm{~cm})$. Rainfall totals for June, July, August, and September were $17.8,5.3,6.3$, and $12.9 \mathrm{~cm}$, respectively.

All lines were planted at the same time. After emergence, SbMyb_ 10a plants were again screened for presence of the transgene using PCR. Because $M$. phaseolina was imported into Nebraska from Texas, only $F$. thapsinum M05A_1J_3b, isolated from a spore trap at Mead, NE (Funnell-Harris et al. 2017), was inoculated onto the field-grown plants. Inoculations were conducted as previously described (Funnell-Harris et al. 2018). In each row (or replication), five plants were randomly chosen and marked with red loop-lock tags $(27.9 \times 2.5 \mathrm{~cm}$; Gempler's, Janesville, WI $)$ and numbered 1 through 5 for pathogen inoculations, and five plants were similarly marked with blue tags for control inoculations. Plants with different inoculations were interspersed within the row. At boot stage, plants were covered with pollination bags to prevent pollen release to the surrounding area. Staggered planting was not possible; therefore, all lines were inoculated at the same time, and lesion lengths were measured on the same day. For inoculations, most of the randomly chosen plants had flowered, with the notable exception of SbMyb_10a plants. The second internode of each stalk was wound inoculated as described above. At 32 DAI the stalk was split longitudinally, and the lesion length was measured. Along with lesion length, maturity and stalk diameters of individual inoculated plants were measured. Because staggered planting was not possible, plant maturity was assessed at three positions on the head (top, middle, and bottom) and was based on a 1 to 8 scale: 1 = vegetative; 2 = vegetative to anthesis; $3=$ anthesis; $4=$ milk; $5=$ milk to soft dough; $6=$ soft dough; $7=$ hard dough; and $8=$ mature. Row heights of six repetitions also were recorded.

Data analysis. Because there were three replications per year, the number of plants per each of six lines per treatment ( $F$. thapsinum and control) per year was 15 . The entire experiment was conducted during two years or growing seasons (repetitions). The data were analyzed using PROC MIXED procedure of SAS/STAT software (SAS 2013). Replication (row) and repetition (year) were considered random effects. Plant line and treatment were considered fixed effects. The dataset was analyzed for Levene's homogeneity of variance and appropriate adjustments incorporated using the REPEATED/GROUP option. The LSM and SE were reported; differences in LSM were considered significant at $P \leq 0.05$. Pearson correlations were generated for the response variables lesion length, plant stage, and stalk diameter using the PROC CORR procedure in SAS/STAT software.

\section{Results}

Stalk rot inoculations of monolignol overexpression lines in the greenhouse. Heights and basal stalk diameters were taken of transgenic and wild-type plants, because these dimensions could affect lesion length (Table 1). It had been shown that plant heights of all 
three $S b M y b 60$ lead events were significantly less than the wild-type, but plant heights were not significantly different for $S b C C o A O M T$ overexpression events (Scully et al. 2016; Tetreault et al. 2018). In the current study, plant heights of the $S b M y b 60$ lines at maturity also were significantly less than the wild-type; however, the plant heights

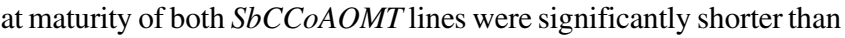
the wild-type (Table 1). Plant heights for $S b P A L, B m r 2$, and $S b C 3 H$ overexpression lines also were significantly shorter than wild-type (Table 1). Stalk diameters of $S b P A L$ lead events were similar to the wild-type line; however, the other overexpression constructs had at least one line with a significantly different stalk diameter from the wild-type. For $S b M y b 60$ overexpression lines, it had been shown that stalk diameters of SbMyb_10a and SbMyb_2a were similar to the wild-type, but SbMyb_15a stalks had significantly smaller mean diameters (Scully et al. 2018). In the current study, the mean stalk diameter of SbMyb_15a was significantly less than the wild-type, but the diameter of SbMyb_2a was greater (Table 1). SbCCoAOMT_9a had a greater mean stalk diameter, whereas Bmr2_6a and SbC3H_3a had smaller stalk diameters than the wild-type (Table 1). In no case was there a significant interaction of plant height $(P \geq 0.17)$ or stalk diameter $(P \geq 0.11)$ with inoculum (i.e., treatments were randomly applied).

When $S b P A L$ overexpression lines and the wild-type were compared for mean lesion lengths following inoculations with stalk pathogens, effects of repetition, line, and inoculum were significant (Table 2). There were no significant differences between the overexpression lines and wild-type when inoculated with $F$. thapsinum $(P \geq$ 0.41) (Fig. 2A). When the SbPAL lines were inoculated with $M$. phaseolina, SbPAL_4a had significantly larger mean lesion lengths than the wild-type and SbPAL_3b $(P \leq 0.05)$. Mean lengths of discolorations as a result of control inoculations were significantly less than mean lesion lengths as a result of pathogen inoculations $(P<0.01)$ (Fig. 2A). Correlations of lesion length on individual lines compared with plant height or stalk diameter were not significant (Table 3); coefficients were significant when inoculating all three lines with $F$. thapsinum for both measurements $(P \leq 0.02)$ but not with $M$. phaseolina $(P \geq 0.06)$ or the control $(P \geq 0.26)$.

Inoculations of $S b M y b 60$ and $S b C C o A O M T$ overexpression and wild-type lines with stalk pathogens were conducted in the same repetitions. Effects of repetition, line, and treatment were significantly different (Table 2). For SbMyb60 overexpression lines and the wild-type, mean lesion lengths of $F$. thapsinum-inoculated plants were shorter for SbMyb_10a and SbMyb_15a $(P \leq 0.03)$, but there were no significant differences when comparing lead event, SbMyb_ 2a and the wild-type $(P=0.24)$ (Fig. $2 \mathrm{~B})$. There were no significant differences in mean lesion lengths between each overexpression line and wild-type when inoculated with $M$. phaseolina $(P \geq 0.20)$. For inoculations of SbCCoAOMT overexpression lines and wild-type with $F$. thapsinum, significantly smaller mean lesion lengths resulted for SbCCoAOMT_9a $(P=0.03)$ but not SbCCoAOMT_28b $(P=$ 0.21 ) (Fig. 2C). After inoculation with $M$. phaseolina, there were no significant differences between mean lesion length resulting on SbCCoAOMT_9a $(P=0.21)$ or SbCCoAOMT_28b $(P=0.07)$ compared with the wild-type. Mean lengths of discoloration following control inoculations were significantly shorter than mean lesion lengths as a result of pathogen inoculations for all lines $(P<0.01)$ (Fig. 2B and C). When correlation analyses were conducted, comparing lesion length with either plant height or stalk diameter in individual lines, significant coefficients were found for SbMyb_10a and for SbCCoAOMT_28 for both measurements (Table 3). Across all SbMyb60 and SbCCoAOMT transgenic lines and the wild-type, correlation coefficients were significant for inoculations with either $F$. thapsinum or $M$. phaseolina $(P<0.01)$ but not the control $(P \geq$ 0.58). To indicate whether plant height may have influenced lesion measurements for each treatment of each $S b M y b 60$ overexpression event, Pearson correlation coefficients were generated for individual lines (SbMyb_2a, SbMyb_10a, SbMyb_15a, and wild-type) comparing lesion lengths with plant height for each inoculum $(F$. thapsinum, M. phaseolina, and control). Again, correlations were significant for pathogen inoculations of SbMyb_10a plants, $F$. thapsinum $(r=$ $0.5288 ; P=0.01)$, and $M$. phaseolina $(r=0.7266 ; P<0.01)$, but not the control inoculation $(r=0.3050 ; P=0.16)$. Inoculation of wild-type plants with $F$. thapsinum also resulted in significant correlations of height with lesion length $(r=0.4383 ; P=0.04)$. All other line-treatment combinations did not result in significant correlations $(P \geq 0.07)$.

When $B m r 2$ overexpression lines were inoculated with stalk pathogens, there were significant differences in repetition or treatment but not line, or the interactions of line with repetition and/or inoculum (Table 2). There were no significant differences in mean lesion lengths between the lead events, Bmr2_2a and Bmr2_6a, and the wild-type line when inoculated with $F$. thapsinum $(P \geq$ $0.30)$ or M. phaseolina $(P \geq 0.49)$ (Fig. 2D). Mean lengths of discolorations following control inoculation were significantly less than mean lesion lengths following pathogen inoculations $(P<$ 0.01) (Fig. 2D). There were no significant correlations of mean lesion length on individual lines with plant height or stalk diameter (Table 3). Additionally, there were no significant correlations with plant height or stalk diameter when considering each inocu$\operatorname{lum}(P \geq 0.13)$.

For inoculations of $\mathrm{SbC} 3 \mathrm{H}$ overexpression lines and the wild-type, there was a significant effect of repetition and treatment but not of line, and their interactions also were not significant (Table 2). There were no significant differences between SbC3H_2 or SbC3H_3 and the wild-type for both $F$. thapsinum $(P \geq 0.32)$ and M. phaseolina $(P$ $\geq 0.23$ ) inoculations (Fig. 2E). Mean discoloration lengths as a result of control inoculation were significantly less than mean lesion lengths from pathogen inoculations $(P<0.01)$ (Fig. 2E). There were no significant correlations of mean lesion length on individual lines with plant height or stalk diameter (Table 3). Also, there were no significant correlations of plant height or stalk diameter with each inoculum $(P \geq 0.07)$.

Table 2. Analysis of variance of fixed effects (repetition [R], transgenic or wild-type line [E], and treatment $[\mathrm{T}]$ ) and interactions for inoculation of transgenic lines carrying an overexpressed gene from monolignol biosynthesis with Fusarium thapsinum, Macrophomina phaseolina, and control compared with wild-type ${ }^{\mathrm{z}}$

\begin{tabular}{|c|c|c|c|c|c|c|c|c|}
\hline \multirow[b]{3}{*}{ Effect } & \multicolumn{8}{|c|}{ Summary statistics from type 3 tests of fixed effects } \\
\hline & \multicolumn{2}{|c|}{ SbPAL } & \multicolumn{2}{|c|}{ SbMyb60, SbCCoAOMT } & \multicolumn{2}{|c|}{ Bmr2 } & \multicolumn{2}{|c|}{$\mathrm{SbC} 3 \mathrm{H}$} \\
\hline & $F$ value & $\operatorname{Pr}>\boldsymbol{F}$ & $F$ value & $\operatorname{Pr}>F$ & $F$ value & $\operatorname{Pr}>\boldsymbol{F}$ & $F$ value & $\operatorname{Pr}>\boldsymbol{F}$ \\
\hline $\mathrm{R}$ & 10.69 & $<0.01$ & 17.15 & $<0.01$ & 3.62 & 0.03 & 9.08 & $<0.01$ \\
\hline E & 2.69 & 0.01 & 2.72 & 0.02 & 1.00 & 0.37 & 2.09 & 0.13 \\
\hline $\mathrm{R} \times \mathrm{E}$ & 2.94 & 0.01 & 2.67 & $<0.01$ & 1.33 & 0.26 & 1.09 & 0.36 \\
\hline $\mathrm{T}$ & 249.97 & $<0.01$ & 205.31 & $<0.01$ & 61.70 & $<0.01$ & 55.10 & $<0.01$ \\
\hline $\mathrm{R} \times \mathrm{T}$ & 4.69 & 0.01 & 16.68 & $<0.01$ & 1.64 & 0.17 & 0.30 & 0.88 \\
\hline $\mathrm{E} \times \mathrm{T}$ & 1.37 & 0.17 & 1.60 & 0.11 & 0.65 & 0.63 & 0.48 & 0.75 \\
\hline $\mathrm{R} \times \mathrm{E} \times \mathrm{T}$ & 1.27 & 0.23 & 1.21 & 0.25 & 1.40 & 0.20 & 1.09 & 0.38 \\
\hline
\end{tabular}

${ }^{\mathrm{z}}$ The response variable was lesion length $(\mathrm{mm})$. Overexpression was accomplished using the $35 \mathrm{~S}$ promoter from the cauliflower mosaic virus. $S b M y b 60$ encodes for a transcription factor, $S b P A L$ encodes for phenylalanine ammonia lyase, $S b C C o A O M T$ encodes for caffeoyl coenzyme A (CoA) 3-O-methyltransferase, $B m r 2$ encodes for 4-coumarate:CoA ligase, and $S b C 3 H$ encodes for coumaroyl shikimate 3-hydroxylase. The $S b M y b 60$ and $S b C C o A O M T$ lines were assessed together. 
Field response of lines overexpressing $S b M y b 60$ and SbCCoAOMT to $F$. thapsinum. Because all lines were planted at the same time, plant heights, growth stages, and stalk diameters were noted for field-grown plants. The transgenic lines overexpressing $S b M y b 60$ were significantly shorter than the wild-type line, whereas the lines overexpressing $S b C C o A O M T$ were not significantly different in height than the wild-type (Table 4). Because plant maturity can affect responses to stalk pathogens (Bandara et al. 2016), plant stage was noted for individual plants, based on a 1 to 8 scale. The wildtype lines were in the milk to soft dough stages (Table 4). Only SbCCoAOMT_28b was at a similar stage as the wild-type, whereas all other lines were at earlier stages, especially the $S b M y b 60$ overexpression lines. Mean stalk diameter of line SbCCoAOMT_9a was not significantly different from wild-type; however, diameters of all other transgenic lines were either significantly larger (SbMyb_2a;
$P<0.01)$ or smaller (SbMyb_10a, SbMyb_15a, SbCCoAOMT_ $28 \mathrm{a} ; P \leq 0.01$ ) than wild-type (Table 4 ).

When inoculated with $F$. thapsinum, effects of line, inoculum, and repetition (year) were significant (Table 5). For the lead events of SbMyb60 overexpression lines, all had mean lesion lengths not significantly different than the wild-type $(P \geq 0.11)$ (Fig. 3). For $S b C C o A O M T$ overexpression lines, SbCCoAOMT_9a had a mean lesion length significantly larger than wild-type $(P=0.02)$, whereas SbCCoAOMT_28b had a larger mean lesion length but not significantly different from wild-type $(P=0.08)$. Mean lesion lengths for all $F$. thapsinum inoculations were significantly greater than responses of control inoculations on the same line $(P<0.01)$ (Fig. $3)$; however, the wound response of SbMyb_10a was significantly shorter than that of wild-type $(P=0.01)$. Pearson correlation coefficients were generated comparing lesion length with either growth
A SbPAL

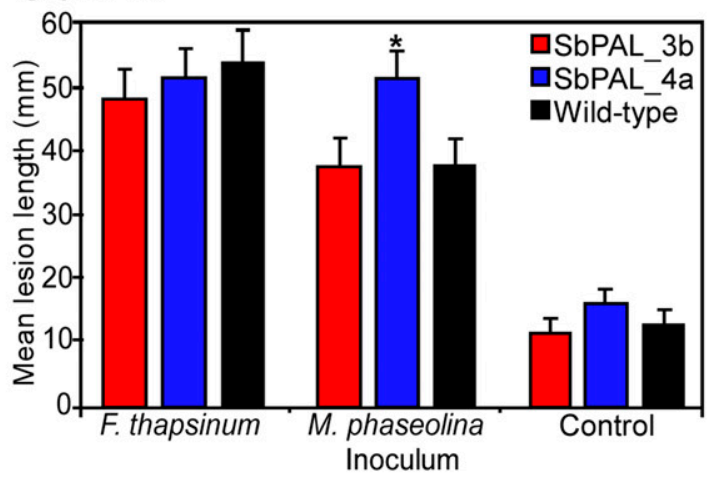

B SbMyb60

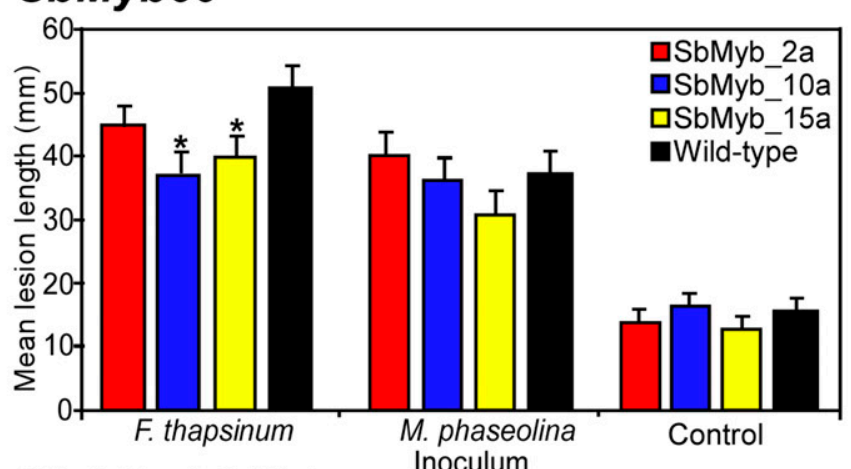

C SbCCOAOMT

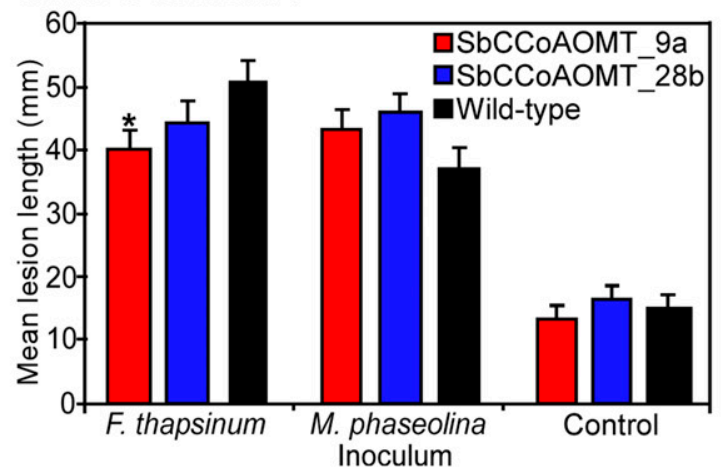

\section{Bmr2}

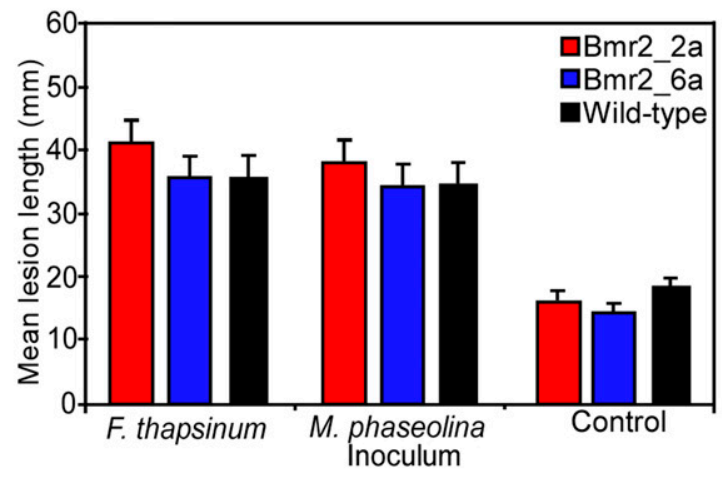

$\mathrm{E} \mathrm{SbC3H}$

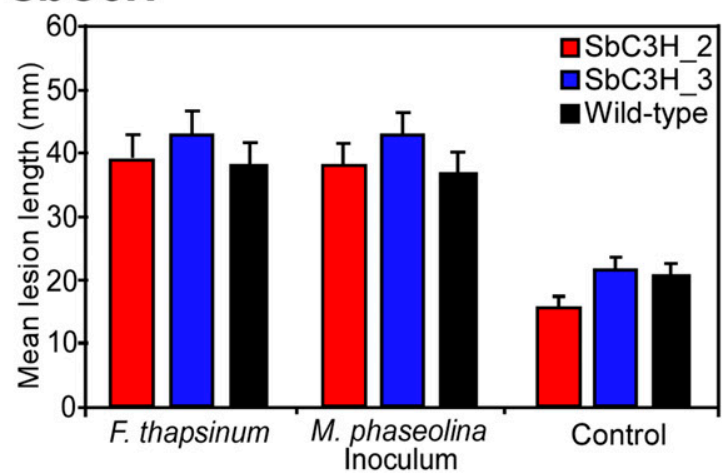

Fig. 2. Lesion lengths $(\mathrm{mm})$ resulting on transgenic sorghum lines overexpressing genes involved in the monolignol biosynthesis pathway to the stalk pathogens Fusarium thapsinum (Fusarium stalk rot) and Macrophomina phaseolina (charcoal rot). Each gene was overexpressed using the cauliflower mosaic virus E35S promoter by transformation into sorghum line RTx430 (wild-type). Greenhouse-grown plants of each transgenic line and the wild-type were wound inoculated within 3 weeks of boot stage with one of the two stalk pathogens or control (potato dextrose broth). Thirty-two days after inoculation, stalks were split longitudinally, and lengths of lesions or discoloration as a result of wounding were measured. A, Lines overexpressing the gene encoding for phenylalanine ammonia lyase (SbPAL). B, Lines overexpressing the gene encoding the transcription factor that regulates genes in the monolignol pathway (SbMyb60). C, Lines overexpressing the gene encoding for the enzyme caffeoyl coenzyme $A(C o A)$ 3-0-methyltransferase (SbCCoAOMT). D, Lines overexpressing the gene encoding for the enzyme 4-coumarate:CoA ligase (Bmr2). E, Lines overexpressing the gene encoding for $p$-coumarate 3-hydrolylase $(\mathrm{SbC} 3 \mathrm{H})$. Asterisks indicate that mean lesion length is significantly different from that on wild-type plants at $P \leq 0.05$. Control inoculations resulted in responses significantly smaller than those following fungal inoculations $(P<0.01)$. 
stage or stalk diameter. The only case in which lesion length was associated with maturity was with SbMyb_10a (Table 6). There were no significant correlations of lesion length with stalk diameter.

\section{Discussion}

Sorghum genes encoding a transcription factor and four different enzymes in the monolignol biosynthesis pathway were overexpressed in transgenic plants, and these overexpression lines, along with the wild-type, were assessed for response to stalk pathogens. Because such lines could be valuable in future efforts to develop sorghum as a dedicated bioenergy crop in thermal processes (Sanna 2014) or a source for renewable biochemicals (Arevalo-Gallegos et al. 2017; Gupta et al. 2016), it was necessary to screen these lines for responses to stalk pathogens. In nearly every case, except for one SbPAL line challenged with $M$. phaseolina (greenhouse) and one SbCCoAOMT line challenged with $F$. thapsinum (field), the transgenic lines were not more susceptible to both stalk pathogens than wild-type. Thus, increased expression of steps in monolignol biosynthesis should not render plants more susceptible to stalk pathogens. On the other hand, increased resistance was observed in two SbMyb60 overexpression lines and one SbCCoAOMT overexpression line when inoculated with $F$. thapsinum in the greenhouse

Table 3. Pearson correlation coefficients $(r)$ and significance levels $(P)$ for comparisons of lesion lengths with plant heights and stalk diameters of greenhouse-grown transgenic sorghum plants overexpressing genes associated with the monolignol biosynthesis pathway ${ }^{2}$

\begin{tabular}{|c|c|c|}
\hline \multirow[b]{2}{*}{ Construct line } & \multicolumn{2}{|c|}{$\begin{array}{c}\text { Pearson correlation coefficient } \\
\text { significance level }\end{array}$} \\
\hline & Plant height & $\overline{\text { Stalk diameter }}$ \\
\hline \multicolumn{3}{|l|}{$S b P A L$} \\
\hline \multirow[t]{2}{*}{ SbPAL_3b } & 0.0253 & 0.1199 \\
\hline & 0.8657 & 0.4170 \\
\hline \multirow[t]{2}{*}{ SbPAL_4a } & -0.0863 & 0.0963 \\
\hline & 0.5598 & 0.5196 \\
\hline \multirow[t]{2}{*}{ Wild-type } & 0.0881 & -0.0091 \\
\hline & 0.5606 & 0.9514 \\
\hline \multicolumn{3}{|c|}{$S b M y b$ and $S b C C o A O M T$} \\
\hline \multirow[t]{2}{*}{ SbMyb_2a } & 0.1133 & 0.1840 \\
\hline & 0.3468 & 0.1244 \\
\hline \multirow[t]{2}{*}{ SbMyb_10a } & 0.2483 & 0.4218 \\
\hline & 0.0368 & 0.0003 \\
\hline \multirow[t]{2}{*}{ SbMyb_15a } & 0.1106 & -0.0231 \\
\hline & 0.3621 & 0.8493 \\
\hline \multirow[t]{2}{*}{ SbCCoAOMT_9a } & 0.0167 & 0.1566 \\
\hline & 0.8896 & 0.1889 \\
\hline \multirow[t]{2}{*}{ SbCCoAOMT_28b } & 0.4082 & 0.2698 \\
\hline & 0.0005 & 0.0239 \\
\hline \multirow[t]{2}{*}{ Wild-type } & 0.0203 & 0.1003 \\
\hline & 0.8665 & 0.4089 \\
\hline \multicolumn{3}{|l|}{$B m r 2$} \\
\hline \multirow[t]{2}{*}{ Bmr2_2a } & 0.1445 & -0.0639 \\
\hline & 0.2258 & 0.5939 \\
\hline \multirow[t]{2}{*}{ Bmr2_6a } & 0.0365 & 0.2114 \\
\hline & 0.7627 & 0.0812 \\
\hline \multirow[t]{2}{*}{ Wild-type } & -0.0113 & 0.0498 \\
\hline & 0.9251 & 0.6780 \\
\hline \multicolumn{3}{|l|}{$\mathrm{SbC} 3 \mathrm{H}$} \\
\hline \multirow[t]{2}{*}{ SbC3H_2b } & -0.1742 & -0.2035 \\
\hline & 0.1463 & 0.0887 \\
\hline \multirow[t]{2}{*}{$\mathrm{SbC} 3 \mathrm{H} \_3 \mathrm{a}$} & 0.0340 & 0.1796 \\
\hline & 0.7783 & 0.1340 \\
\hline \multicolumn{3}{|c|}{$\begin{array}{l}\text { z SbMyb60 encodes for a transcription factor, } S b P A L \text { encodes for phenylala- } \\
\text { nine ammonia lyase, SbCCoAOMT encodes for caffeoyl coenzyme A } \\
(\mathrm{CoA}) 3-O \text {-methyltransferase, Bmr2 encodes for } 4 \text {-coumarate:CoA ligase, } \\
\text { and } S b C 3 H \text { encodes for coumaroyl shikimate } 3 \text {-hydroxylase. The } S b M y b 60 \\
\text { and } S b C C O A O M T \text { lines were assessed together. Transgenic lines and wild- } \\
\text { type line, RTx } 430 \text {, were inoculated with the stalk pathogens Fusarium thap- } \\
\text { sinum or Macrophomina phaseolina or with a broth control. Coefficients are } \\
\text { considered significant when } P \leq 0.05 \text {. }\end{array}$} \\
\hline
\end{tabular}

(Fig. 2); however, the hypothesis that increasing either expression of steps in monolignol biosynthesis or the entire pathway activity would result in increased resistance to stalk pathogens was disproven for the most part.

In previous research, sorghum $b m r$ lines were as resistant as nearisogenic wild-type or even more resistant, depending on the line and pathogen (Funnell-Harris et al. 2014, 2017). Such observations were attributed to accumulation of phenolic compounds (soluble and cellwall bound) (Palmer et al. 2008) that are potentially inhibitory to the pathogen (Boutigny et al. 2009; Ferruz et al. 2016; Funnell-Harris et al. 2014, 2017). This may be one explanation as to why, in the current study, SbMyb60 overexpression lines had mean lesion lengths similar to wild-type, or even significantly smaller than wild-type, in both greenhouse and field assessments to stalk pathogens (Figs. 2B and 3). It had been previously shown that $S b M y b 60$ overexpression resulted in significantly greater accumulation of lignin in cell walls and of wall-bound metabolites derived from the monolignol pathway, which include ferulic and caffeic acids that were previously shown to inhibit $M$. phaseolina and $F$. thapsinum growth in vitro, respectively (Funnell-Harris et al. 2014; Scully et al. 2016). Additionally, genes associated with SAM metabolism, one of three cofactors necessary for monolignol biosynthesis, were also upregulated in these lines, which suggests $S b M y b 60$ not only activates monolignol synthesis but also the substrate and a cofactor required for this pathway (Scully et al. 2018). SAM, a cofactor for many methyltransferases in animals, fungi, plants, and bacteria (Liscombe et al. 2012), also serves as a substrate for ethylene synthesis in plants (Amir 2010; Roje 2006). The ethylene signaling pathway has been associated with response to pathogens and is necessary for defense against many soil-borne necrotrophic pathogens (Berrocal-Lobo

Table 4. Heights, maturity, and stalk diameters at time of lesion measurement on field-grown plants ${ }^{\mathrm{z}}$

\begin{tabular}{lccc}
\hline Line & $\begin{array}{c}\text { Row } \\
\text { height }(\mathbf{c m})\end{array}$ & Maturity & $\begin{array}{c}\text { Stalk } \\
\text { diameter }(\mathbf{m m})\end{array}$ \\
\hline SbMyb_2a & $127.08 \pm 1.50 \mathrm{a}$ & $3.88 \pm 0.06 \mathrm{a}$ & $21.78 \pm 0.45 \mathrm{a}$ \\
SbMyb_10a & $120.00 \pm 1.50 \mathrm{~b}$ & $1.53 \pm 0.18 \mathrm{~b}$ & $15.00 \pm 0.48 \mathrm{~d}$ \\
SbMyb_15a & $107.08 \pm 1.50 \mathrm{c}$ & $3.80 \pm 0.09 \mathrm{a}$ & $14.48 \pm 0.32 \mathrm{~d}$ \\
SbCCoAOMT_9a & $133.75 \pm 1.50 \mathrm{~d}$ & $5.15 \pm 0.11 \mathrm{c}$ & $18.85 \pm 0.33 \mathrm{bc}$ \\
SbCCoAOMT_28b & $134.58 \pm 1.50 \mathrm{~d}$ & $5.65 \pm 0.12 \mathrm{~d}$ & $18.25 \pm 0.37 \mathrm{c}$ \\
Wild-type & $136.25 \pm 1.50 \mathrm{~d}$ & $5.81 \pm 0.09 \mathrm{~d}$ & $19.42 \pm 0.27 \mathrm{~b}$ \\
\hline
\end{tabular}

${ }^{\mathrm{z}} \mathrm{SbMyb60}$ and $\mathrm{SbCCOAOMT}$ overexpression lines with wild-type were planted during the growing seasons of 2017 and 2018. Row heights were determined in six replicate plots in each season. Maturity at time of lesion measurement was assessed at three positions on the head (top, middle, and bottom), using a 1 to 8 scale: 1 = vegetative; $2=$ vegetative to anthesis; 3 $=$ anthesis; $4=$ milk; $5=$ milk to soft dough; $6=$ soft dough; $7=$ hard dough; and $8=$ mature. Stalk diameters were also determined. Least squares means (LSM) and standard errors are shown. LSM with different letters are significantly different at $P \leq 0.05$.

Table 5. Analysis of variance of fixed effects (year [Y], transgenic or wildtype line $[\mathrm{E}]$, and treatment $[\mathrm{T}]$ ) and interactions for inoculation of fieldgrown transgenic lines overexpressing $S b M y b 60$ or $S b C C o A O M T$ with Fusarium thapsinum or control compared with wild-type ${ }^{\mathrm{z}}$

\begin{tabular}{lrr}
\hline & \multicolumn{2}{c}{$\begin{array}{c}\text { Summary statistics from type } 3 \text { tests of } \\
\text { fixed effects }\end{array}$} \\
\cline { 2 - 4 } Effect & $\boldsymbol{F}$ value & $\boldsymbol{P r}>\boldsymbol{F}$ \\
\hline $\mathrm{Y}$ & 7.17 & 0.01 \\
$\mathrm{E}$ & 10.02 & $<0.01$ \\
$\mathrm{Y} \times \mathrm{E}$ & 1.61 & 0.16 \\
$\mathrm{~T}$ & 229.71 & $<0.01$ \\
$\mathrm{Y} \times \mathrm{T}$ & 3.23 & 0.07 \\
$\mathrm{E} \times \mathrm{T}$ & 2.26 & 0.05 \\
$\mathrm{Y} \times \mathrm{E} \times \mathrm{T}$ & 1.72 & 0.14 \\
\hline
\end{tabular}

${ }^{\mathrm{z}}$ The response variable was lesion length $(\mathrm{mm})$. The constructs were $S b M y b 60$, which encodes for a transcription factor, and SbCCOAOMT, which encodes for caffeoyl coenzyme A 3-O-methyltransferase. 
and Antonio 2004; Geraats et al. 2003; Okubara and Paulitz 2005; Zhang et al. 2007). Arabidopsis thaliana lines that expressed SbSAM synthase from a wild potato (Solanum brevidens) had enhanced SAM biosynthesis along with upregulation of ethylene biosynthetic genes (Kim et al. 2015). Overexpression of SbSAM synthase also induced three Pathogenesis-related genes in A. thaliana, which supports its role in plant defense. Expression of yeast spermidine synthase ( $y S p d$ Syn), which requires SAM as a substrate, in tomato (Solanum lycopersicum), resulted in increased susceptibility to the necrotrophic fungal pathogen Botrytis cinerea but not to two other pathogens (the necrotrophic pathogen Alternaria solani and the hemibiotrophic bacterial pathogen Pseudomonas syringae), and larvae of a chewing insect (Manduca sexta); resistance to B. cinerea was rescued by exogenous application of ethylene precursors that included SAM (Nambeesan et al. 2012). In cotton (Gossypium barbadense), the gene for the ethylene response-related factor GbERF1-like was both downregulated and overexpressed, resulting in increased susceptibility and resistance, respectively, to the necrotrophic fungus Verticillium dahliae (Guo et al. 2016). Following inoculation of both overexpression and wild-type lines, transcripts of monolignol

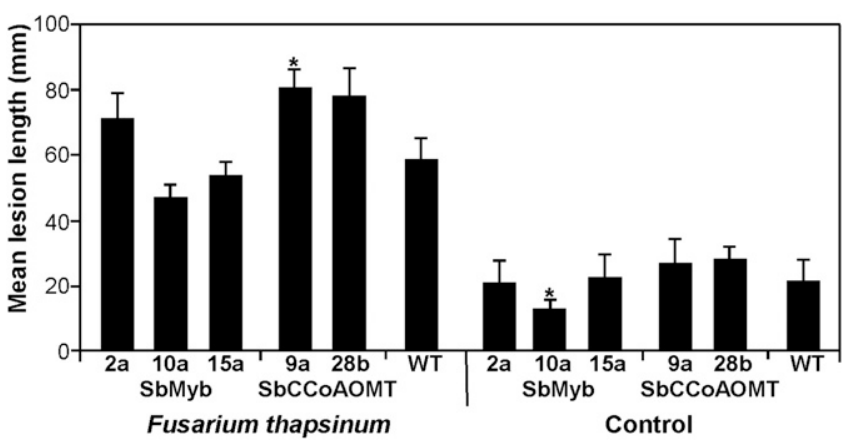

Fig. 3. Mean lesion lengths $(\mathrm{mm})$ of field-grown transgenic sorghum plants overexpressing the gene for transcription factor SbMyb60 and the gene for the enzyme caffeoyl coenzyme A 3-0-methyltransferase (SbCCoAOMT), along with the wild-type line, RTx430, inoculated with Fusarium thapsinum. Each gene was overexpressed using the cauliflower mosaic virus E35S promoter by transformation into sorghum line RTx430 (wild-type). Plants of each transgenic line and the wildtype were wound inoculated at flowering, and then 32 days after inoculation stalks were split longitudinally, and the lengths of lesions or discolorations as a result of wounding were measured. Field inoculations were conducted over 2 years (2017 and 2018). Asterisk indicates that mean lesion length or wound discoloration of transgenic line is significantly different from that on wild-type plants $(P \leq 0.02)$. Responses of control inoculations were significantly less than those following fungal inoculation $(P<0.01)$.

Table 6. Pearson correlation coefficients $(r)$ and significance levels $(P)$ for comparisons of lesion lengths with plant maturity and stalk diameters of field-grown plants overexpressing the genes $S b M y b 60$ and $S b C C o A O M T^{\mathrm{z}}$

\begin{tabular}{lcc}
\hline & \multicolumn{2}{c}{$\begin{array}{c}\text { Pearson correlation coefficient } \\
\text { significance level }\end{array}$} \\
\cline { 2 - 3 } Construct line & Maturity & Stalk diameter \\
\hline SbMyb_2a & -0.1382 & -0.1311 \\
& 0.2919 & 0.3180 \\
SbMyb_10a & 0.3925 & 0.1095 \\
SbMyb_15a & 0.0028 & 0.4176 \\
SbCCoAOMT_9a & -0.0085 & -0.0446 \\
SbCCoAOMT_28b & 0.9489 & 0.7376 \\
Wild-type & 0.0521 & -0.0775 \\
& 0.6927 & 0.5564 \\
& 0.0948 & 0.0694 \\
& 0.4710 & 0.5983 \\
& 0.1932 & -0.1318 \\
& 0.1463 & 0.3196 \\
\hline
\end{tabular}

${ }^{\mathrm{z}}$ Transgenic lines and wild-type line, RTx430, were inoculated with the stalk pathogen Fusarium thapsinum or with a broth control. Coefficients are considered significant when $P \leq 0.05$. biosynthetic genes that included $P A L, C 3 H$, and $C C O A O M T$ accumulated, and total lignin (as determined by the Klason method) increased. Additionally, there was a significantly greater accumulation of lignin in uninoculated overexpressing plants and significantly lower accumulation in downregulated lines compared with the wild-type, which possibly affected responses to $V$. dahliae. Taken together, these previous studies indicate a connection between SAM, ethylene, the monolignol biosynthesis pathway and responses to pathogens (Bhuiyan et al. 2007; Jin et al. 2017).

In the current study, pleiotropic effects of overexpression of SbMyb60 in sorghum lines previously observed (Scully et al. 2016, 2018) were reflected in differential responses of the three overexpression lines to the two stalk pathogens in greenhouse assessments, especially following inoculations with $F$. thapsinum (Fig. 2). Pearson coefficients indicated there were no significant correlations between plant height or stalk diameter and lesion length (or response from control inoculations) for SbMyb_2a and SbMyb_15a, but for SbMyb_10a, there were significant correlations (Table 2). SbMyb_ 10a had the highest relative expression level of $S b M y b 60$ in stalks, highest expression levels of genes encoding for PAL, 4CL, cinnamyl-CoA reductase (CCR), CCoAOMT, and CAD, highest levels of $p$-coumaric acid, syringic acid, and vanillic acid, and highest levels of all three forms of lignin, compared with SbMyb_2a, SbMyb_15a, and the wild-type lines (Scully et al. 2016). Therefore, multiple factors may have contributed to reduced lesion lengths in the SbMyb_10a line, which included the anatomical changes resulting from overexpression of $S b M y b 60$ in these plants.

It has been previously shown that overexpression of $S b C C o A O M T$ increased soluble and wall-bound hydroxycinnamic acids, although lignin and polysaccharide contents did not change (Tetreault et al. 2018). In A. thaliana, overexpression of the lipid transfer protein gene, AZELAIC ACID INDUCED 1 (AZII) resulted in increased transcription of $C C O A O M T$ and $C C R$, enzymes acting in consecutive steps that lead to $\mathrm{G}$ and $\mathrm{S}$ lignin, but no other genes in the monolignol pathway were induced (Gao et al. 2015). The AZI1 protein is associated with generation or transmission of the defense signal, salicylic acid, necessary for systemic acquired resistance (Jung et al. 2009), which implies a role for CCOAOMT and CCR and/or their products in induced resistance. In the current study, greenhouse inoculations of the SbCCoAOMT lines with $F$. thapsinum resulted in lesions not significantly different (SbCCoAOMT_28b) or smaller (SbCCoAOMT_9a) than wild-type (Fig. 2C). However, in field inoculations using another $F$. thapsinum isolate, lesion lengths were significantly greater (SbCCoAOMT_9a), and it could be argued that lesions resulting on SbCCoAOMT_28b $(P=0.08)$ also were larger than those on wild-type (Fig. 3). Additionally, greenhouse inoculations with $M$. phaseolina resulted in mean lesion lengths that tended to be larger than that on the wild-type, and again it could be argued that line SbCCoAOMT_28b had increased susceptibility to $M$. phaseolina compared with the wild-type $(P=0.07)$. Therefore, it appears that overexpression of $S b C C o A O M T$ in sorghum may actually negatively affect resistance responses to the two stalk diseases examined in this study. In maize, the AvrE family type II effector and pathogenicity factor, WtsE, from the bacterial pathogen Pantoea stewartii ssp. stewartii, alone could increase flux through the phenylpropanoid pathway, by increasing expression of $P A L$ and $4 C L$, but resulted in increased susceptibility, which the authors propose as "misregulated induction" of the phenylpropanoid pathway (Asselin et al. 2015). Thus, in the current study, plants with overexpression of $S b C C O A O M T$ grown under greenhouse conditions with increased susceptibility to $M$. phaseolina and under field conditions with increased susceptibility to $F$. thapsinum may have been owing to changes in accumulation of intermediates and flux through the monolignol synthesis pathway, which altered defense responses.

In field inoculations with $F$. thapsinum, $S b M y b 60$ overexpression lines appeared to respond similarly to the pathogen as in greenhouse studies, but for $S b C C o A O M T$ overexpression lines, results in the greenhouse and the field were not consistent (Figs. 2C and 3). Differences in responses between field- and greenhouse-grown transgenic plants have been observed with decreased fitness or increased disease 
susceptibility in field-grown transgenic switchgrass (Panicum virgatum) and increased accumulation of deoxynivalenol in field-grown barley (Hordeum vulgare) engineered to detoxify the mycotoxin compared with greenhouse-grown plants (Baxter et al. 2015, 2018; Manoharan et al. 2006).

The lines overexpressing $S b P A L, B m r 2$, and $S b C 3 H$ have not been as thoroughly studied as $S b M y b 60$ and $S b C C o A O M T$, because the original project goal was to increase energy availability for bioenergy, and these lines did not display increases in lignin or energy. However, it is currently unknown whether cell wall components have been altered. Previously, constitutive expression of heterologous $P A L$ transgenes in tobacco (Nicotiana tabacum) and A. thaliana resulted in plants resistant to multiple pathogens (Kim and Hwang 2014; Way et al. 2011). PAL is well-known to be associated with resistance to pathogens (Ganapathy et al. 2016; Wojtasik et al. 2016). $4 C L$ has also been associated with defense responses to pathogens (Reinold and Hahlbrock 1996), whereas $\mathrm{C} 3 \mathrm{H}$ has been shown to be involved in responses during colonization by beneficial microorganisms (Battini et al. 2016). In the current study, when plants overexpressing each of these enzymes were inoculated with the two stalk pathogens, there were no significant differences in mean lesion lengths compared with the corresponding wild-type, except for one SbPAL overexpression line, SbPAL_4a, which was significantly more susceptible to M. phaseolina than the wild-type (Fig. 2A, D, and E). Mean lesion lengths, used to determine the response to $M$. phaseolina inoculation, compared between individual transgenic lines from the same construct, were variable not only for $S b P A L$ but also for $S b M y b 60(P \geq 0.06)$ lines. Because $S b M y b 60$ is a transcriptional activator of multiple genes, this is not surprising. However, responses of the same lines to $F$. thapsinum inoculation seemed to be more consistent $(P \geq 0.10)$. Differential responses between events (lines) with the same construct to multiple pathogens have been previously reported (Ghanta et al. 2011; Goto et al. 2015).

In summary, lines overexpressing genes involved in the monolignol biosynthesis pathway, SbMyb60 (Scully et al. 2016), $S b C C o A O M T$ (Tetreault et al. 2018), SbPAL, Bmr2, or $S b C 3 H$ (this work), were inoculated with two pathogens under greenhouse conditions, which are associated with the greatest stalk disease problems of sorghum in the United States: F. thapsinum and M. phaseolina. Additionally, the SbMyb60 and SbCCoAOMT transgenic lines, along with wild-type, were assessed in the field for response to $F$. thapsinum. SbMyb60 overexpression lines responded similarly to the pathogens, and two of the three lines exhibited increased resistance to $F$. thapsinum in greenhouse inoculations. Although $\mathrm{SbCCoAOMT \text {lines }}$ exhibited smaller mean lesion lengths after inoculation with $F$. thapsinum in the greenhouse, these lines appeared to be more susceptible in the field study; these same lines tended to exhibit increased susceptibility to M. phaseolina. $S b P A L, B m r 2$, and $S b C 3 H$ overexpression lines were all as resistant as the wild-type lines to $F$. thapsinum. For M. phaseolina, Bmr2 and $\mathrm{SbC} 3 \mathrm{H}$ overexpression lines were as resistant as the wild-type lines, but one $S b P A L$ lead event was more susceptible than the wild-type to this pathogen. To our knowledge, this is the first examination of response to necrotrophic pathogens from any crop overexpressing genes in the monolignol biosynthesis. This research provides valuable information for using sorghum lines with increased expression of monolignol biosynthesis genes as feedstock for thermochemical conversion of biomass (Carvalho et al. 2017; Habyarimana et al. 2016) or production of renewable products from the phenylpropanoid pathway in pharmaceuticals or cosmetics (Hauck et al. 2013; Massey et al. 2014; Parveen et al. 2014).

\section{Acknowledgments}

The authors thank P. Tenopir for planting and overseeing, and J. Toy for maintenance and quality trait data, of transgenic plants in field plots; and A. Coomer, M. Khasin, Z. Duray, L. Bernhardson, M. Kilts, E. Blusys, and Z. Van Roy for technical assistance with laboratory, greenhouse, and field assessments. Mention of trade names or commercial products in this article is solely for the purpose of providing specific information and does not imply recommendation or endorsement by the U.S. Department of Agriculture. The U.S. Department of Agriculture (USDA) prohibits discrimination in all its programs and activities on the basis of race, color, national origin, age, disability, and where applicable, sex, marital status, familial status, parental status, religion, sexual orientation, genetic information, political beliefs, reprisal, or because all or part of an individual's income is derived from any public assistance program. (Not all prohibited bases apply to all programs.) Persons with disabilities who require alternative means for communication of program information (Braille, large print, audiotape, etc.) should contact USDA's TARGET Center at (202) 720-2600 (voice and TDD). To file a complaint of discrimination, write to USDA, Director, Office of Civil Rights, 1400 Independence Avenue, S.W., Washington, D.C. 20250-9410, or call (800) 795-3272 (voice) or (202) 720-6382 (TDD). USDA is an equal opportunity provider and employer.

\section{Literature Cited}

Ameen, A., Yang, X., Chen, F., Tang, C., Du, F., Fahad, S., and Xie, G. H. 2017. Biomass yield and nutrient uptake of energy sorghum in response to nitrogen fertilizer rate on marginal land in a semi-arid region. Bioenerg. Res. 10: 363-376.

Amir, R. 2010. Current understanding of the factors regulating methionine content in vegetative tissues of higher plants. Amino Acids 39:917-931.

Arevalo-Gallegos, A., Ahmad, Z., Asgher, M., Parra-Saldivar, R., and Iqbal, H. M. N. 2017. Lignocellulose: A sustainable material to produce value-added products with a zero waste approach—A review. Int. J. Biol. Macromol. 99:308-318.

Asselin, J. A. E., Lin, J., Perez-Quintero, A. L., Gentzel, I., Majerczak, D., Opiyo, S. O., Zhao, W., Paek, S.-M., Kim, M. G., Coplin, D. L., Blakeslee, J. J., and Mackey, D. 2015. Perturbation of maize phenylpropanoid metabolism by an AvrE family type III effector from Pantoea stewartii. Plant Physiol. 167: 1117-1135.

Azadi, P., Inderwildi, O. R., Farnood, R., and King, D. A. 2013. Liquid fuels, hydrogen and chemicals from lignin: A critical review. Renew. Sustain. Energy Rev. 21:506-523.

Bandara, Y. M. A. Y., Tesso, T. T., Bean, S. R., Dowell, F. E., and Little, C. R. $2017 \mathrm{~b}$. Impacts of fungal stalk rot pathogens on physicochemical properties of sorghum grain. Plant Dis. 101:2059-2065.

Bandara, Y. M. A. Y., Tesso, T. T., Zhang, K., Wang, D., and Little, C. R. 2018. Charcoal rot and Fusarium stalk rot diseases influence sweet sorghum sugar attributes. Ind. Crops Prod. 112:188-195.

Bandara, Y. M. A. Y., Weerasooriya, D. K., Tesso, T. T., and Little, C. R. 2016. Stalk rot fungi affect leaf greenness (SPAD) of grain sorghum in a genotype-and growth-stage-specific manner. Plant Dis. 100:2062-2068.

Bandara, Y. M. A. Y., Weerasooriya, D. K., Tesso, T. T., and Little, C. R. 2017a Stalk rot diseases impact sweet sorghum biofuel traits. Bioenerg. Res. 10:26-35

Bandara, Y. M. A. Y., Weerasooriya, D. K., Tesso, T. T., Prasad, P. V. V., and Little, C. R. 2017c. Stalk rot fungi affect grain sorghum yield components in an inoculation stage-specific manner. Crop Prot. 94:97-105.

Barcelos, C. A., Maeda, R. N., Santa Anna, L. M. M., and Pereira, N., Jr. 2016. Sweet sorghum as a whole-crop feedstock for ethanol production. Biomass Bioenergy 94:46-56.

Battini, F., Bernardi, R., Turrini, A., Agnolucci, M., and Giovannetti, M. 2016. Rhizophagus intraradices or its associated bacteria affect gene expression of key enzymes involved in the rosmarinic acid biosynthetic pathway of basil. Mycorrhiza 26:699-707.

Baxter, H. L., Mazarei, M., Dumitrache, A., Natzke, J. M., Rodriguez, M., Jr., Gou, J., Fu, C., Sykes, R. W., Turner, G. B., Davis, M. F., Brown, S. D., Davison, B. H., Wang, Z.-Y., and Stewart, C. N., Jr. 2018. Transgenic miR156 switchgrass in the field: Growth, recalcitrance and rust susceptibility. Plant Biotechnol. J. 16:39-49.

Baxter, H. L., Poovaiah, C. R., Yee, K. L., Mazarei, M., Rodriguez, M., Jr., Thompson, O. A., Shen, H., Turner, G. B., Decker, S. R., Sykes, R. W., Chen, F., Davis, M. F., Mielenz, J. R., Davison, B. H., Dixon, R. A., and Stewart, C. N., Jr. 2015. Field evaluation of transgenic switchgrass plants overexpressing $P v M Y B 4$ for reduced biomass recalcitrance. Bioenerg. Res. 8: 910-921.

Berrocal-Lobo, M., and Antonio, M. 2004. Ethylene response factor 1 mediates Arabidopsis resistance to the soilborne fungus Fusarium oxysporum. Mol Plant-Microbe Interact. 17:763-770.

Bhuiyan, N. H., Liu, W., Liu, G., Selvaraj, G., Wei, Y., and King, J. 2007. Transcriptional regulation of genes involved in the pathways of biosynthesis and supply of methyl units in response to powdery mildew attack and abiotic stresses in wheat. Plant Mol. Biol. 64:305-318.

Bhuiyan, N. H., Selvaraj, G., Wei, Y., and King, J. 2009. Gene expression profiling and silencing reveal that monolignol biosynthesis plays a critical role in penetration defence in wheat against powdery mildew invasion. J. Exp. Bot. 60:509-521.

Boateng, A. A., Weimer, P. J., Jung, H. G., and Lamb, J. F. S. 2008. Response of thermochemical and biochemical conversion processes to lignin concentration in alfalfa stems. Energy Fuels 22:2810-2815.

Bout, S., and Vermerris, W. 2003. A candidate-gene approach to clone the sorghum Brown midrib gene encoding caffeic acid $O$-methyltransferase. Mol. Genet. Genomics 269:205-214.

Boutigny, A.-L., Barreau, C., Atanasova-Penichon, V., Verdal-Bonnin, M.-N., Pinson-Gadais, L., and Richard-Forget, F. 2009. Ferulic acid, an efficient inhibitor of type B trichothecene biosynthesis and Tri gene expression in Fusarium liquid cultures. Mycol. Res. 113:746-753. 
Carvalho, W. D., Santana, J. A., Jr., de Oliveira, T. J. P., and Ataide, C. H. 2017. Fast pyrolysis of sweet sorghum bagasse in a fluidized bed reactor: Product characterization and comparison with vapors generated in analytical pyrolysis. Energy 131:186-197.

Chang, T.-H., Lin, Y.-H., Chen, K.-S., Huang, J.-W., Hsiao, S.-C., and Chang, P.F. L. 2015. Cell wall reinforcement in watermelon shoot base related to its resistance to Fusarium wilt caused by Fusarium oxysporum f. sp. niveum. J. Agric. Sci. 153:296-305.

Claflin, L. E., and Giorda, L. M. 2002. Stalk rots of sorghum. Pages 185-190 in: Sorghum and Millets Diseases. J. F. Leslie, ed. Iowa State Press, Ames, IA.

Cui, J. D., Qiu, J. Q., Fan, X. W., Jia, S. R., and Tan, Z. L. 2014. Biotechnological production and applications of microbial phenylalanine ammonia lyase: A recent review. Crit. Rev. Biotechnol. 34:258-268.

Eudes, A., Dutta, T., Deng, K., Jacquet, N., Sinha, A., Venites, V. T., Baidoo, E. E. K., Richel, A., Sattler, S. E., Northen, T. R., Singh, S., Simmons, B. A., and Loque, D. 2017. SbCOMT (Bmr12) is involved in the biosynthesis of tricinlignin in sorghum. PLoS One 12:e0178160.

Ferruz, E., Loran, S., Herrera, M., Gimenez, I., Bervis, N., Barcena, C., Carraminana, J. J., Juan, T., Herrera, A., and Arino, A. 2016. Inhibition of Fusarium growth and mycotoxin production in culture medium and in maize kernels by natural phenolic acids. J. Food Prot. 79:1753-1758.

Fornalé, S., Rencoret, J., Garcia-Calvo, L., Capellades, M., Encina, A., Santiago, R., Rigua, J., Gutierrez, A., del Rio, J.-C., and Caparros-Ruiz, D. 2015. Cell wall modifications triggered by the down-regulation of coumarate 3hydroxylase-1 in maize. Plant Sci. 236:272-282.

Franke, R., Hemm, M. R., Denault, J. W., Ruegger, M. O., Humphreys, J. M., and Chapple, C. 2002. Changes in secondary metabolism and deposition of an unusual lignin in the ref8 mutant of Arabidopsis. Plant J. 30:47-59.

Funnell, D. L., and Pedersen, J. F. 2006. Reaction of sorghum lines genetically modified for reduced lignin content to infection by Fusarium and Alternaria spp. Plant Dis. 90:331-338.

Funnell-Harris, D. L., O'Neill, P. M., and Sattler, S. E. 2018. Field response of near-isogenic brown midrib sorghum lines to fusarium stalk rot, and response of wildtype lines to controlled water deficit. Plant Pathol. 67:1474-1482.

Funnell-Harris, D. L., O’Neill, P. M., Sattler, S. E., Gries, T., Berhow, M. A., and Pedersen, J. F. 2017. Response of sorghum stalk pathogens to brown midrib plants and soluble phenolic extracts from near isogenic lines. Eur. J. Plant Pathol. 148:941-953.

Funnell-Harris, D. L., Pedersen, J. F., and Sattler, S. E. 2010. Alteration in lignin biosynthesis restricts growth of Fusarium spp. in brown midrib sorghum. Phytopathology 100:671-681.

Funnell-Harris, D. L., Prom, L. K., and Pedersen, J. F. 2013. Isolation and characterization of the grain mold fungi Cochliobolus and Alternaria spp. from sorghum using semiselective media and DNA sequence analyses. Can. J. Microbiol. 59:87-96

Funnell-Harris, D. L., Sattler, S. E., and Pedersen, J. F. 2014. Response of Fusarium thapsinum to sorghum brown midrib lines and to phenolic metabolites. Plant Dis. 98:1300-1308.

Ganapathy, G., Keerthi, D., Aswati Nair, R., and Pillai, P. 2016. Correlation of phenylalanine ammonia lyase (PAL) and tyrosine ammonia lyase (TAL) activities to phenolics and curcuminoid content in ginger and its wild congener, Zingiber zerumbet following Pythium myriotylum infection. Eur. J. Plant Pathol. 145:777-785.

Gao, H., Wang, X.-Y., Han, Y.-Y., Du, G.-L., Feng, H., and Xu, Z.-Q. 2015. Accumulation of the azelaic acid-induced protein ASI1 affects lignin synthesis and deposition in Arabidopsis thaliana. Plant Growth Regul. 75: 317-330.

Geiser, D. M., del Mar Jimenez-Gasco, M., Kang, S., Makalowska, I., Veeraraghavan, N., Ward, T. J., Zhang, N., Kuldua, G. A., and O'Donnell, K. 2004. FUSARIUM-id v. 1.0: A DNA sequence database for identifying Fusarium. Eur. J. Plant Pathol. 110:473-479.

Geraats, B. P. J., Bakker, P. A. H. M., Lawrence, C. B., Achuo, E. A., Hofte, M., and van Loon, L. C. 2003. Ethylene-insensitive tobacco shows differentially altered susceptibility to different pathogens. Phytopathology 93:813-821.

Ghanta, S., Battacharyya, D., Sinha, R., Banerjee, A., and Chattopadhyay, S. 2011. Nicotiana tabacum overexpressing gamma-ECS exhibits biotic stress tolerance likely through NPR1-dependent salicylic acid-mediated pathway. Planta 233: 895-910.

Goto, S., Sasakura-Shimoda, F., Suetsugu, M., Selvaraj, M. G., Hayashi, N., Yamazaki, M., Ishitani, M., Shimono, M., Sugano, S., Matsushita, A., Tanabata, T., and Takatsuji, H. 2015. Development of disease-resistant rice by optimized expression of WRKY45. Plant Biotechnol. J. 13:753-765.

Gunnaiah, R., and Kushalappa, A. C. 2014. Metabolomics deciphers the host resistance mechanisms in wheat cultivar Sumai-3, against trichothecene producing and non-producing isolates of Fusarium graminearum. Plant Physiol. Biochem. 83:40-50.

Guo, W., Jin, L., Miao, Y., He, X., Hu, Q., Guo, K., Zhu, L., and Zhang, X. 2016. An ethylene response-related factor, GbERF1-like, from Gossypium barbadense improves resistance to Verticillium dahliae via activating lignin synthesis. Plant Mol. Biol. 91:305-318.

Gupta, V. K., Kubicek, C. P., Berrin, J. G., Wilson, D. W., Courturier, M., Berlin, A., Filho, E. X. F., and Ezeji, T. 2016. Fungal enzymes for bio-products from sustainable and waste biomass. Trends Biochem. Sci. 41:633-645.
Habyarimana, E., Lorenzoni, C., Marudelli, M., Redaelli, R., and Amaducci, S. 2016. A meta-analysis of bioenergy conversion relevant traits in sorghum landraces, lines and hybrids in the Mediterranean region. Ind. Crops Prod. 81:100-109.

Hajdukiewicz, P., Svab, Z., and Maliga, P. 1994. The small versatile $p P Z P$ family of Agrobacterium binary vectors for plant transformation. Plant Mol. Biol. 25: 989-994.

Hauck, B., Gallagher, J. A., Morris, M., Leemans, D., and Winters, A. L. 2013 Soluble phenolic compounds in fresh and ensiled orchard grass (Dactylis glomerata L.), a common species in permanent pastures with potential as a biomass feedstock. J. Agric. Food Chem. 62:468-475.

Jardine, D. J., and Leslie, J. F. 1992. Aggressiveness of Gibberella fujikuroi (Fusarium moniliforme) isolates to grain sorghum under greenhouse conditions. Plant Dis. 76:897-900.

Jin, Y., Ye, N., Zhu, H., Wang, J., Jiang, L., and Zhang, J. 2017. Calciumdependent protein kinase CPK28 targets methionine adenosyltransferases for degradation by the $26 \mathrm{~S}$ proteasome and affects ethylene biosynthesis and lignin deposition in Arabidopsis. Plant J. 90:304-318.

Jun, S.-Y., Sattler, S. A., Cortez, G. S., Vermeriss, W., Sattler, S. E., and Kang, C. H. 2018. Biochemical and structural analysis of substrate specificity of a phenylalanine ammonia-lyase. Plant Physiol. 176:1452-1468.

Jung, H. G., Tschaplinski, T. J., Wang, L., Glazebrook, J., and Greenberg, J. T. 2009. Priming in systemic plant immunity. Science 324:89-91.

Kelly, L. A., Tan, Y. P., Ryley, M. J., and Aitken, E. A. B. 2017. Fusarium species associated with stalk rot and head blight of grain sorghum in Queensland and New South Wales Australia. Plant Pathol. 66:1413-1423.

Kim, D. S., and Hwang, B. K. 2014. An important role of the pepper phenylalanine ammonia-lyase gene (PAL1) in salicylic acid-dependent signalling of the defence response to microbial pathogens. J. Exp. Bot. 65:2295-2306.

Kim, S. H., Kim, S. H., Palaniyandi, S. A., Yang, S. H., and Suh, J.-W. 2015 Expression of potato $S$-adenosyl-L-methionine synthase (SbSAMS) gene altered developmental characteristics and stress responses in transgenic Arabidopsis plants. Plant Physiol. Biochem. 87:84-91.

Kumari, N., Sharma, I., Alam, A., and Sharma, V. 2015. Screening of sorghum genotypes and biochemical changes for resistance to damage caused by Macrophomina phaseolina. Arch. Phytopathol. Pflanzenschutz 48:760-775.

Liscombe, D. K., Louie, G. V., and Noel, J. P. 2012. Architectures, mechanisms and molecular evolution of natural product methyltransferases. Nat. Prod. Rep. 29:1238-1250.

Madanayake, B. N., Gan, S., Eastwick, C., and Ng, H. K. 2017. Biomass as an energy source in coal co-firing and its feasibility enhancement via pretreatment techniques. Fuel Process. Technol. 159:287-305.

Manoharan, M., Dahleen, L. S., Hohn, T. M., Neate, S. M., Yu, X.-H., Alexander, N. J., McCormick, S. P., Bregitzer, P., Schwarz, P. B., and Horsley, R. D. 2006. Expression of 3-OH trichothecene acetyltransferase in barley (Hordeum vulgare L.) and effects on deoxynivalenol. Plant Sci. 171:699-706.

Massey, A. R., Reddivari, L., and Vanamala, J. 2014. The dermal layer of sweet sorghum (Sorghum bicolor) stalk, a byproduct of biofuel production and source of unique deoxyanthocyanidins, has more antiproliferative and proapoptotic activity than the pith in p53 variants of HCT116 and colon cancer stem cells. J. Agric. Food Chem. 62:3150-3159.

Moerschbacher, B., Heck, B., Kogel, K. H., Obst, O., and Reisener, H. J. 1986. An elicitor of the hypersensitive lignification response in wheat leaves isolated from the rust fungus Puccinia graminis f. sp. tritici. II. Induction of enzymes correlated with the biosynthesis of lignin. Z. Naturforsch. 41:839-844.

Mughogho, L. K., and Rosenberg, G. 1984. Sorghum Root and Stalk Rots-A Critical Review. ICRISAT, Patancheru, AP, India.

Nambeesan, S., AbuQamar, S., Laluk, K., Mattoo, A. K., Mcikelbart, M. V., Ferruzzi, M. G., Mengiste, T., and Handa, A. K. 2012. Polyamines attenuate ethylene-mediated defense responses to abrogate resistance to Botrytis cinerea in tomato. Plant Physiol. 158:1034-1045.

Naoumkina, M. A., Zhao, Q., Gallego-Giraldo, L., Dai, X., Zhao, P. X., and Dixon, R. A. 2010. Genome-wide analysis of phenylpropanoid defence pathways. Mol. Plant Pathol. 11:829-846.

Nicholson, R. L., and Hammerschmidt, R. 1992. Phenolic compounds and their role in disease resistance. Annu. Rev. Phytopathol. 30:369-389.

Okubara, P. A., and Paulitz, T. C. 2005. Root defense responses to fungal pathogens: A molecular perspective. Plant Soil 274:215-226.

Oliver, A. L., Pedersen, J. F., Grant, R. J., Klopfenstein, T. J., and Jose, H. D. 2005 Comparative effects of the sorghum $b m r-6$ and $b m r-12$ genes: II. Grain yield, stover yield, and stover quality in grain sorghum. Crop Sci. 45:2240-2245.

Palmer, N. A., Sattler, S. E., Saathoff, A. J., Funnell, D., Pedersen, J. F., and Sarath, G. 2008. Genetic background impacts soluble and cell wall-bound aromatics in brown midrib mutants of sorghum. Planta 229:115-127.

Parveen, I., Wilson, T., Threadgill, M. D., Luyten, J., Roberts, R. E., Robson, P. R. H., Donnison, I. S., Hauck, B., and Winters, A. L. 2014. Screening for potential co-products in a Miscanthus sinensis mapping family by liquid chromatography with mass spectrometry detection. Phytochemistry 105:186-196.

Pedersen, J. F., Toy, J. J., Funnell, D., Sattler, S. E., Oliver, A. L., and Grant, R. J. 2008. Registration of BN611, AN612, BN612, and RN613 sorghum genetic stocks with stacked $b m r-6$ and $b m r-12$. J. Plant Regist. 2:258-262.

Pillonel, C., Mulder, M. M., Boon, J. J., Forster, B., and Binder, A. 1991 Involvement of cinnamyl-alcohol dehydrogenase in the control of lignin formation in Sorghum bicolor L. Moench. Planta 185:538-544. 
Ragauskas, A. J., Beckham, G. T., Biddy, M. J., Chandra, R., Chen, F., Davis, M. F., Davison, B. H., Dixon, R. A., Gilna, P., Keller, M., Langan, P., Naskar, A. K., Saddler, J. N., Tschaplinski, T. J., Tuskan, G. A., and Wyman, C. E. 2014. Lignin valorization: Improving lignin processing in the biorefinery. Science 344:1246843.

Rajewski, J. F., and Francis, C. A. 1991. Defoliation effects on grain fill, stalk rot, and lodging of grain sorghum. Crop Sci. 31:353-359.

Rao, K. N., Reddy, V. S., Williams, R. J., and House, L. R. 1980. The ICRISAT charcoal rot resistance program. Pages 315-321 in: Proceedings of the International Workshop on Sorghum Diseases. R. A. F. R. J. Williams and L. K. Mughogho, eds. International Crops Research Institute for the Semi-Arid Tropics, Hyderabad, India.

Reddy, M. S. S., Chen, F., Shadle, G., Jackson, L., Aljoe, H., and Dixon, R. A. 2005. Targeted down-regulation of cytochrome P450 enzymes for forage quality improvement in alfalfa (Medicago sativa L.). Proc. Natl. Acad. Sci. U.S.A. 102:16573-16578.

Reed, J. E., Partridge, J. E., and Nordquist, P. T. 1983. Fungal colonization of stalks and roots of grain sorghum during the growing season. Plant Dis. 67: 417-420.

Reinold, S., and Hahlbrock, L. 1996. Biphasic temporal and spatial induction patterns of defense-related mRNAs and proteins in fungus-infected parsley leaves. Plant Physiol. 112:131-140.

Roje, S. 2006. S-Adenysyl-L-methionine: Beyond the universal methyl group donor. Phytochemistry 67:1686-1698.

Saballos, A., Sattler, S. E., Sanchez, E., Foster, T. P., Xin, Z., Kang, C. H., Pedersen, J. F., and Vermerris, W. 2012. Brown midrib2 (Bmr2) encodes the major 4-coumarate:coenzyme A ligase involved in lignin biosynthesis in sorghum, (Sorghum bicolor (L.) Moench). Plant J. 70:818-830.

Sanna, A. 2014. Advanced biofuels from thermochemical processing of sustainable biomass in Europe. Bioenerg. Res. 7:36-47.

SAS. 2013. SAS 9.4 Help and Documentation. SAS Institute, Cary, NC.

Sattler, S. E., Saathoff, A. J., Haas, E. J., Palmer, N. A., Funnell-Harris, D. L., Sarath, G., and Pedersen, J. F. 2009. A nonsense mutation in a cinnamyl alcohol dehydrogenase gene is responsible for the sorghum brown midrib6 phenotype. Plant Physiol. 150:584-595.

Scully, E. D., Gries, T., Palmer, N. A., Sarath, G., Funnell-Harris, D. L., Baird, L., Twigg, P., Seravalli, J., Clemente, T. E., and Sattler, S. E. 2018. Overexpression of SbMyb60 in Sorghum bicolor impacts both primary and secondary metabolism. New Phytol. 217:82-104

Scully, E. D., Gries, T., Sarath, G., Palmer, N. A., Baird, L., Serapiglia, M. J., Dien, B. S., Boateng, A. A., Ge, Z., Funnell-Harris, D. L., Twigg, P., Clemente, T. E., and Sattler, S. E. 2016. Overexpression of SbMyb60 impacts phenylpropanoid biosynthesis and alters secondary cell wall composition in Sorghum bicolor. Plant J. 85:378-395.

Steiner, B., Kurz, H., Lemmens, M., and Buerstmayr, H. 2009. Differential gene expression of related wheat lines with contrasting levels of head blight resistance after Fusarium graminearum inoculation. Theor. Appl. Genet. 118: 753-764.

Teixeira, T. P. M., Pimental, L. D., Dias, L. A. S., Parrella, R. A. C., da Paixao, M. Q., and Biesdorf, E. M. 2017. Redefinition of sweet sorghum harvest time: New approach for sampling and decision-making in field. Ind. Crops Prod. 109: 579-586.
Tesso, T. T., Claflin, L. E., and Tuinstra, M. R. 2005. Analysis of stalk rot resistance and genetic diversity among drought tolerant sorghum genotypes. Crop Sci. 45:645-652.

Tesso, T. T., Ochanda, N., Little, C. R., Claflin, L., and Tuinstra, M. R. 2010 Analysis of host plant resistance to multiple Fusarium species associated with stalk rot disease in sorghum [Sorghum bicolor (L.) Moench]. Field Crops Res. 118:177-182.

Tetreault, H. M., Scully, E. D., Gries, T., Palmer, N. A., Funnell-Harris, D. L., Baird, L., Seravalli, J., Dien, B. S., Sarath, G., Clemente, T. E., and Sattler, S. E. 2018. Overexpression of the Sorghum bicolor SbCCoAOMT alters cell wall associated hydroxycinnamoyl groups. PLoS One 13:e0204153.

Uloth, M. B., You, M. P., and Barbetti, M. J. 2015. Host resistance to Sclerotinia stem rot in historic and current Brassica napus and B. juncea varieties: Critical management implications. Crop Pasture Sci. 66:841-848.

Vogel, K. P., Pedersen, J. F., Masterson, S. D., and Toy, J. J. 1999. Evaluation of a filter bag system for NDF, ADF, and IVDMD forage analysis. Crop Sci. 39: 276-279.

Walker, A. M., Hayes, R. P., Youn, B., Vermerris, W., Sattler, S. E., and Kang, C.-H. 2013. Elucidation of the structure and reaction mechanism of sorghum hydroxycinnamoyltransferase and its structural relationship to other coenzyme A-dependent transferases and synthases. Plant Physiol. 162:640-651.

Walter, M. H. 1992. Regulation of lignification in defense. Pages 327-352 in: Genes Involved in Plant Defense. T. Boller and F. Meins, eds. SpringerVerlag, Vienna, Austria.

Way, H. M., Birch, R. G., and Manners, J. M. 2011. A comparison of individual and combined L-phenylalanine ammonia lyase and cationic peroxidase transgenes for engineering resistance in tobacco to necrotrophic pathogens. Plant Biotechnol. Rep. 5:301-308.

Wojtasik, W., Kulma, A., Dyminska, L., Hanuza, J., Czemplik, M., and Szopa, J. 2016. Evaluation of the significance of cell wall polymers in flax infected with a pathogenic strain of Fusarium oxysporum. BMC Plant Biol. 16:75.

Wu, W., Dutta, T., Varman, A. M., Eudes, A., Manalansan, B., Loque, D., and Singh, S. 2017. Lignin valorization: Two hybrid biochemical routes for the conversion of polymeric lignin into value-added chemicals. Sci. Rep. 7:8420.

Wuyts, N., Lognay, G., Verscheure, M., Marlier, M., De Waele, D., and Swennen, R. 2007. Potential physical and chemical barriers to infection by the furrowing nematode Radopholus similis in roots of susceptible and resistant banana (Musa spp.). Plant Pathol. 56:878-890.

Xie, S., Qin, X., Cheng, Y., Laskar, D., Qiao, W., Sun, S., Reyes, L. H., Wang, X. Dai, S. Y., Sattler, S. E., Kao, K., Yang, B., Zhang, X., and Yuan, J. S. 2015. Simultaneous conversion of all cell wall components by an oleaginous fungus without chemi-physical pretreatment. Green Chem. 17:1657-1667.

Zhang, K., Zheng, G., Saul, K., Jiao, Y., Xin, Z., and Wang, D. 2017. Evaluation of the multi-seeded $(m s d)$ mutant of sorghum for ethanol production. Ind. Crops Prod. 97:345-353.

Zhang, Y., Wang, X., Rong, W., Yang, J., Li, Z., Wu, L., Zhang, G., and Ma, Z 2017. Histochemical analyses reveal that stronger intrinsic defenses in Gossypium barbadense than in $G$. hirsutum are associated with resistance to Verticillium dahliae. Mol. Plant-Microbe Interact. 30:984-996.

Zhang, Z., Yao, W.-L., Dong, N., Liang, H.-X., Liu, H.-X., and Huang, R. 2007. A novel ERF transcription activator in wheat and its induction kinetics after pathogen and hormone treatments. J. Exp. Bot. 58:2993-3003. 